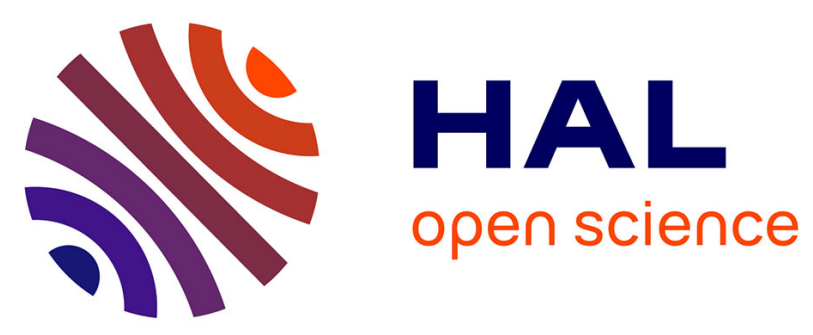

\title{
Molecular-Level Insights into Coker/Straight-Run Gas Oil Hydrodenitrogenation by Fourier Transform Ion Cyclotron Resonance Mass Spectrometry
}

Minh-Tuan Nguyen, Gerhard Pirngruber, Fabien Chainet, Florian Albrieux, Melaz Tayakout-Fayolle, Christophe Geantet

\section{To cite this version:}

Minh-Tuan Nguyen, Gerhard Pirngruber, Fabien Chainet, Florian Albrieux, Melaz Tayakout-Fayolle, et al.. Molecular-Level Insights into Coker/Straight-Run Gas Oil Hydrodenitrogenation by Fourier Transform Ion Cyclotron Resonance Mass Spectrometry. Energy \& Fuels, 2019, 33 (4), pp.3034-3046. 10.1021/acs.energyfuels.8b04432 . hal-02149671

\section{HAL Id: hal-02149671 \\ https://hal-ifp.archives-ouvertes.fr/hal-02149671}

Submitted on 6 Jun 2019

HAL is a multi-disciplinary open access archive for the deposit and dissemination of scientific research documents, whether they are published or not. The documents may come from teaching and research institutions in France or abroad, or from public or private research centers.
L'archive ouverte pluridisciplinaire HAL, est destinée au dépôt et à la diffusion de documents scientifiques de niveau recherche, publiés ou non, émanant des établissements d'enseignement et de recherche français ou étrangers, des laboratoires publics ou privés. 


\section{Molecular level insights into coker/straight run gas oil hydrodenitrogenation by Fourier Transform Ion Cyclotron Resonance Mass Spectrometry}

Minh-Tuan Nguyen ${ }^{1}$, Gerhard D. Pirngruber ${ }^{1 *}$, Fabien Chainet ${ }^{1}$, Florian Albrieux ${ }^{1}$, Mélaz TayakoutFayolle $^{2}$, Christophe Geantet ${ }^{3}$

${ }^{1}$ IFP Energies nouvelles, Rond-point de l'échangeur de Solaize, BP 3, 69360 Solaize, France

${ }^{2}$ Laboratoire d'Automatique et de Génie des Procédés, Université de Lyon, Université Claude Bernard Lyon 1, CNRS/UCBL, UMR 5007,43 Bd du 11 Novembre 1918, 69622 Villeurbanne Cedex, France

${ }^{3}$ Université de Lyon, IRCELYON, UMR 5256/CNRS-Université Lyon 1, 2 avenue Albert Einstein, F-69626

Villeurbanne, France

Email addresses of authors:

1. Minh-Tuan Nguyen: minh-tuan.nguyen@ifpen.fr

2. Gerhard D. Pirngruber: gerhard.pirngruber@ifpen.fr

3. Fabien Chainet : fabien.chainet@ifpen.fr

4. Florian Albrieux : florian.albrieux@ifpen.fr

5. Melaz Tayakout-Fayolle: Tayakout@lagep.univ-lyon1.fr

6. Christophe Geantet: christophe.geantet@ircelyon.univ-lyon1.fr

* Corresponding author: Gerhard D. Pirngruber

Email: gerhard.pirngruber@ifpen.fr 


\begin{abstract}
This paper aims to understand the reactivity of different nitrogen species during the catalytic hydrodenitrogenation (HDN) of a mixture of straight-run gas oil and coker gas oil. Effluents at different HDN conversions were analyzed by Fourier Transform lon Cyclotron Resonance Mass Spectrometry (FTICR/MS), with ElectroSpray Ionization (ESI). Positive ESI (ESI(+)) allows a selective ionization of basic nitrogen compounds, while negative $\mathrm{ESI}(\mathrm{ESI}(-))$ leads to a selective ionization of neutral nitrogen compounds. $\mathrm{FT}-\mathrm{ICR} / \mathrm{MS}$ in $\mathrm{ESI}(+)$ or (-) mode generates distributions of the nitrogen compounds in the basic and neutral class, respectively, according to their carbon number and Double Bond Equivalent (DBE), which is related to the degree of aromaticity and the number of rings. The evolution of the DBE distribution and the carbon number distribution as a function of HDN conversion gives rich information concerning the main reaction pathways and the reactivity of different nitrogen species. For the basic compounds a shift to lower DBE was observed, which was interpreted as the formation of partially hydrogenated or ring-opened intermediates. These intermediates were then slowly converted to the final HDN products. At intermediate conversion levels, especially light compounds were accumulated as intermediates, while the heavy compounds were directly converted to HDN products, probably due to preferential adsorption. The neutral compounds showed a very different behavior. At the early reaction stages, they were quickly converted to HDN products, but at high conversion, the conversion of residual carbazole and tetrahydrobenzocarbazole compounds was completely inhibited. The inhibition was probably provoked by the formation of partially hydrogenated basic intermediates, which were stronger inhibitors than the aromatic pyridine rings in the feed. The contribution of cracking reactions was weak, since the overall carbon number distribution of the nitrogen compounds did not change much during hydrotreating.
\end{abstract}

Key words: hydrodenitrogenation, FT-ICR/MS, Electrospray, nitrogen compounds, Coker gas oil, hydrotreatment, inhibition 


\section{Introduction}

The hydrotreatment of gas oil fractions usually focuses on the removal of sulfur compounds and, secondarily, on decreasing the aromatics content in the fuel. The residual sulfur content in fuels is regulated by legislation, while hydrogenation of aromatics is required in order to improve the cetane number of diesel and the smoke point of kerosene. Organic nitrogen compounds of gas oil fractions are eliminated at the same time in the hydrotreatment process ${ }^{1}$, but the hydrodenitrogenation reaction is often not a limiting factor for reaching the sulfur/cetane specifications. However, there is a rising tendency to valorize gas oils coming from conversion processes of heavier oil fractions (such as vacuum gas oil and residue), for example Light Cycle Oil (LCO) produced by the FCC process or Coker Gas Oil (CGO) produced by coking of residue. LCO and CGO have nitrogen contents of several hundred ppms and are very difficult feeds for hydrotreating. The nitrogen species are known to be strong inhibitors of hydrodesulfurization (HDS) reactions and hydrodearomatization (HDA). Improving the hydrodentirogenation (HDN) activity, therefore, becomes an important issue ${ }^{2-4}$. In the hydrotreating of difficult gasoil feeds with high nitrogen content, stacked beds are frequently used ${ }^{5,6}$, i.e. one alternates a catalyst, which has a high HDS activity with a catalyst, which has a high HDN activity. In order to optimize the synergy between HDS and HDN in a hydrotreating process, it is crucial to understand the reactivity and inhibition effects of the numerous nitrogen species in a gasoil mixture. Although extensive studies on model molecules like quinoline ${ }^{7-10}$ and carbazole ${ }^{11,12}$ have been conducted, however, to our knowledge, the dominating reaction pathways in the HDN reaction network of a real gasoil feed is still limited. The main reason is the complexity of the system and the difficulty to obtain a detailed analysis of reaction intermediates and products at a molecular level.

Recent advances in analytical techniques allow a better identification of the nature of $\mathrm{N}$-containing compounds in a complex matrix of petroleum fractions. The successful implementation of Nitrogen Chemiluminescence Detector (NCD) with comprehensive (two dimensional) gas chromatography facilitates the identification of these nitrogen compounds ${ }^{13-22}$. In heavy gas oil, more than one hundred $\mathrm{N}$ compounds were detected by NCD, including alkyl-indols, alkyl-carbazols, alkyl-benzocarbazols, alkylquinolines, alkyl-benzoquinolines, and alkyl-dibenzoquinolines ${ }^{23}$. High resolution mass spectrometry such 
as Fourier Transform Ion Cyclotron Resonance Mass Spectrometry (FT-ICR/MS) has been also developed for providing a comprehensive identification of heavy compounds in petroleum fractions ${ }^{24-26}$. The compounds can be classified into families having the same carbon number and the same degree of unsaturation (Double Bond Equivalent, DBE) ${ }^{27}$. The DBE for a compound is the sum of double bonds, number of nitrogen atoms in the ring and number of rings (except for nitrogen heterocycle). It is calculated by the formula: $D B E=c-h / 2+n / 2+1$ for $a \mathrm{C}_{n} \mathrm{H}_{n} \mathrm{~N}_{n} \mathrm{O}_{o} \mathrm{~S}_{s}$ molecule.

With the electrospray ionization (ESI) source, the technique can further distinguish basic compounds, which are selectively ionized by positive electrospray ionization (ESI+), and neutral compounds, which are selectively ionized with negative electrospray ionization (ESI-). The technique has been applied to crude oil $^{28}$, (heavy) coker gas oils ${ }^{29-32}$, vacuum gas oil ${ }^{33}$, atmospheric residues ${ }^{34,35}$ and hydrotreating effluents 34-38. In all cases, the FT-ICR/MS analyses found that the majority of nitrogen containing molecules belonged to the so-called $\mathrm{N}_{1}$ class, i.e. with one nitrogen atom in the molecule and no other heteroatoms, but polyheteroatom compounds (i.e. $\mathrm{N}_{1} \mathrm{~S}_{1}, \mathrm{~N}_{1} \mathrm{O}_{1}, \mathrm{~N}_{2}, \ldots$ ) were also present in non-negligible amounts ${ }^{32,34,35}$. However, these polyheteroatom compounds were practically absent in hydrotreated effluents ${ }^{33,39}$. Only the N2 class remains fairly resistant to hydrotreatment ${ }^{40}$. Liu et al. ${ }^{34}$ and Zhang et al. ${ }^{41}$ showed that $\mathrm{N}_{1}$ class species in atmospheric residue and deasphalted oil, respectively, were more easily hydrogenated when they had high aromaticity and/or low carbon number. Oro and Lucy ${ }^{42}$ compared a large set of Light and Heavy Gas Oils, before and after hydrotreating at different temperatures of with different catalysts, using a HPLC preparation in order to fractionate $\mathrm{N}$ compounds families. The composition of the fractions, further analyzed by FTICR-MS clearly depended on the nature of the catalyst used, but unfortunately the composition of the catalysts was not disclosed ${ }^{42}$. Overall, the question of how nitrogen species evolve as a function of HDN conversion and how this evolution depends on catalyst and operating conditions, has not really been addressed in the existing literature. Thus, despite the progress of the analytical techniques, the link to a HDN reaction network has not yet been established.

The interpretation of HDN reaction pathways of a real feed on the basis of mass spectrometric analysis is a daunting task because hydrotreatment can simultaneously remove and generate compounds of the same DBE values. For example, quinoline-type compounds are converted into hydrogenated quinoline or 
pyridine-type compounds, but at the same time they are produced from acridine-type compounds ${ }^{37}$. Moreover, $\mathrm{N}_{1}$ class species might be generated from polyheteroatoms compounds ${ }^{36}$. We can use our knowledge on the HDN of model molecules as a guide for the interpretation of the real feed data. Studies on (benzo)quinoline and carbazole showed that HDN proceeds by the saturation of nitrogen containing aromatic rings followed by the ring opening to produce amine-type compounds, which are rapidly denitrogenated ${ }^{9}$. Both saturation and ring opening reactions lead to the diminution of the DBE value of nitrogen compounds, and thus modify the DBE distribution, but do not change their carbon number (Figure 1). For basic compounds, the change of DBE is -2 by ring hydrogenation (or -3 for the last aromatic ring) and -1 by ring opening. For neutral compounds, the saturation of five-ring compounds can be performed by adding only two hydrogen atoms; in that case the DBE change is - 1 . Since model molecule tests are normally not presented in the form of DBE families, we translated our recent data on quinoline $(\mathrm{DBE}=7)$ conversion in the format that would be seen by FT-ICR/MS: in the course of hydrotreating, DBE $=5$ (tetrahydroquinolines) and DBE $=2$ compounds (decahydroquinoline) were predominant in the reaction mixture (Figure 2). A major difference in the conversion of basic and neutral compounds in model molecule tests is that in the case of neutral compounds, only few partially hydrogenated intermediates (i.e. lower DBE intermediates) were detected before full HDN conversion 11,12,43. In particular, hexahydrocarbazole intermediates (which are basic intermediates and would be detected by ESI(+)-FTICR/MS, see Figure 1) have never been found in significant concentrations during hydrotreating of carbazole. 


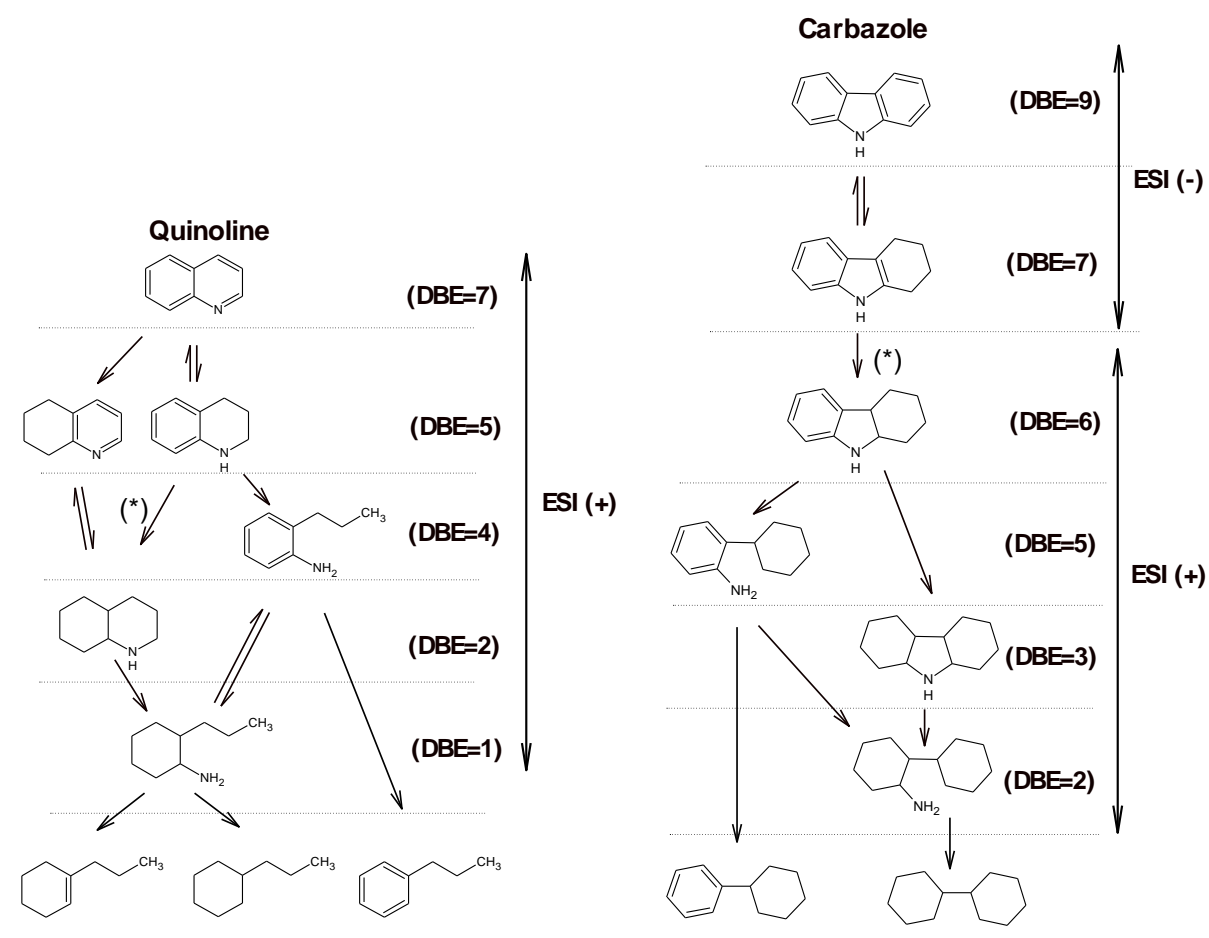

Figure 1: Reaction network of quinoline and carbazole HDN with DBE descriptions ${ }^{5,6}{ }^{*}$ : the rate determining step)

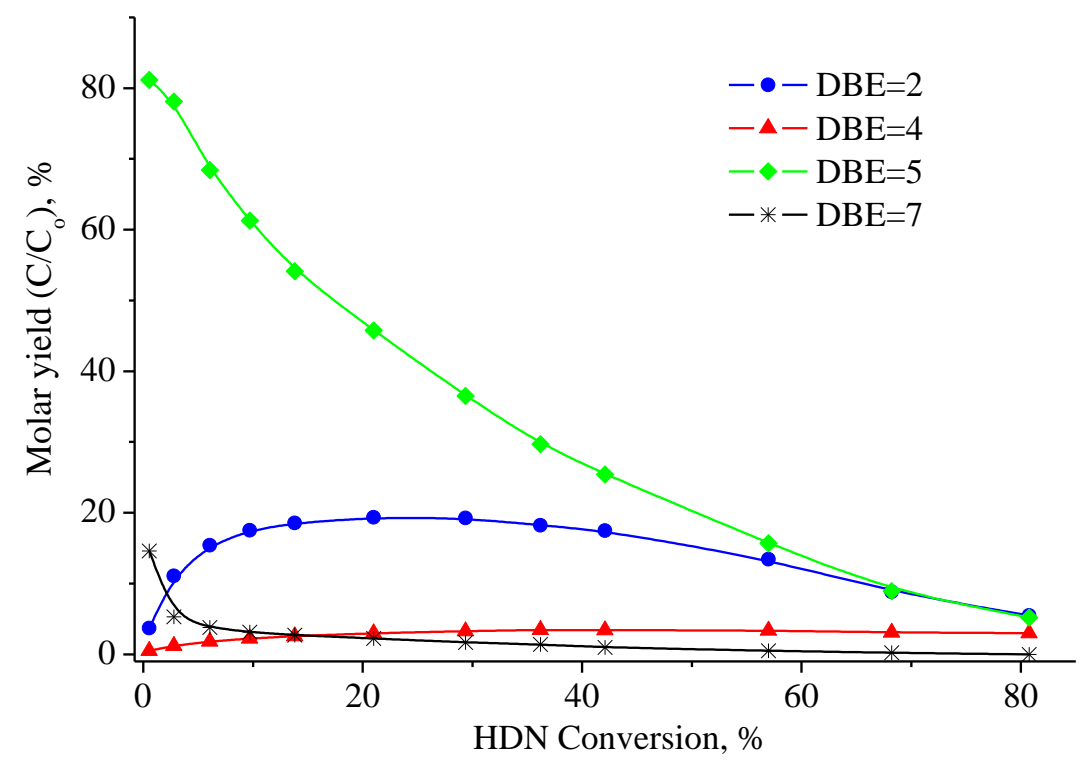

Figure 2: HDN conversion of quinoline over $\mathrm{NiMo}(P) / A S A$ catalyst, expressed in the form of DBE-families, adapted from ${ }^{9}$ 
A major difference between model molecule feeds and real gas oil mixtures is that the aromatic nitrogen compounds in gas oil are highly substituted by alkyl chains. If cracking of alkyl chains occurs during hydrotreating, it will not modify the DBE but decrease the carbon number distribution.

In this work, which is based on the PhD thesis of M.T. Nguyen ${ }^{44}$, hydrotreated effluents of gas oil mixture with high nitrogen content were analyzed by FT-ICR/MS. A macroscopic analysis of the corresponding catalytic tests was presented elsewhere ${ }^{45}$; we analyzed the global evolution of neutral and basic nitrogen species (similar to the previous work of Qiang et al. ${ }^{46}$ ), but could not provide molecular details. In this work, we interpret the HDN reaction pathways on a molecular level, which becomes possible by analyzing the evolution of DBE families and carbon number distribution as a function of global HDN conversion. The reactivity of the different nitrogen compound families is compared and the major pathways of the HDN reaction network of a gas oil feed are identified.

\section{Experimental and methodology}

\subsection{Materials and catalytic tests}

A mixture of straight run gas oil and coker gas oil (50/50 wt \%) was used as the gas oil feed in this study. Table 1 summarizes physicochemical properties of the gas oil mixture. The basic nitrogen content in gas oil mixture (determined by potentiometric titration by IFPEN 9626) represented $43 \%$ of total nitrogen content.

Table 1: Physicochemical properties of the gas oil feed

\begin{tabular}{lcc}
\hline & Unit & Value \\
\hline Total nitrogen & wppm & $703 \pm 53$ \\
Basic nitrogen & wppm & $290 \pm 23$ \\
Total sulfur & wt $\%$ & 1.44 \\
Density at $15^{\circ} \mathrm{C}$ & $\mathrm{g} / \mathrm{cm}^{3}$ & $0.865(\mathrm{API}=32.08)$ \\
D86 distillation & & \\
$5 \%$ & ${ }^{\circ} \mathrm{C}$ & 190 \\
$20 \%$ & ${ }^{\circ} \mathrm{C}$ & 236 \\
$50 \%$ & ${ }^{\circ} \mathrm{C}$ & 300
\end{tabular}




\begin{tabular}{lll}
$80 \%$ & ${ }^{\circ} \mathrm{C}$ & 357 \\
$95 \%$ & ${ }^{\circ} \mathrm{C}$ & 397 \\
\hline
\end{tabular}

Catalytic tests were carried out over a NiMo-based silica-alumina supported catalyst (NiMo(P)/ASA) whose properties were reported in a previous paper ${ }^{9}$. Prior to catalytic tests, the catalyst was sulfided exsitu in a $15 \% \mathrm{v} / \mathrm{v} \mathrm{H}_{2} \mathrm{~S}$ in $\mathrm{H}_{2}$ gas mixture, at a flow rate of $1.3 \mathrm{~L} / \mathrm{g}_{\text {cata. }} \mathrm{h}$, and $673 \mathrm{~K}$, for $4 \mathrm{~h}$. The size of catalyst particles was in the range of $80-125 \mu \mathrm{m}$. After the sulfidation, $0.9 \mathrm{~g}$ of catalyst was loaded in a tubular reactor $(7 \mathrm{~mm}$ of internal diameter), between two layers of $\mathrm{SiC}(\approx 3.5 \mathrm{~g}$ per layer, 35-74 $\mu \mathrm{m} \mathrm{SiC}$ size particles). The catalytic tests were performed in a three phases fixed-bed reactor in up-flow model ${ }^{47}$. During an operating cycle, the liquid hourly space velocity (LHSV) was varied in the range of 2-6 $\mathrm{h}^{-1}$. Reaction conditions are summarized as follows:

- Reaction temperature: $633 \mathrm{~K}$

- $\quad$ Ratio $\mathrm{H}_{2}$ /Gas Oil: $400 \mathrm{NL}$ gas/L liquid

- Catalyst: NiMo(P)/ASA, 80-125 $\mu \mathrm{m}$, sulfided ex-situ

- Pressure: $5 \mathrm{MPa}$

- $\quad$ LHSV: in the range of $2.1-5.8 \mathrm{~h}^{-1}$

Table 2 provides important characteristics, i.e. total nitrogen and basic nitrogen contents, of the gas oil feed and hydrotreated effluents. The total and the basic nitrogen content were respectively determined by chemiluminescence based on ASTM D4629 and IFPEN method 9626 following ASTM D2896.

Table 2: Summary of gas oil feed and hydrotreated samples with HDN conversions for analyses

\begin{tabular}{cccccc}
\hline $\mathrm{N}^{\circ}$ & $\begin{array}{c}\text { LHSV, } \\
\mathrm{h}^{-1}\end{array}$ & $\begin{array}{c}\text { HDN conversion, } \\
\%\end{array}$ & $\begin{array}{c}{[\mathrm{N}],} \\
\text { Wppm }\end{array}$ & $\begin{array}{c}{[\mathrm{N}] \text { basic, }} \\
\text { wppm }\end{array}$ & $\%[\mathrm{~N}]$ basic \\
\hline Feed & - & - & 703 & 289 & 41.1 \\
\hline Effluent 1 & 5.8 & 71 & 204 & 152 & 74.5 \\
Effluent 2 & 4.6 & 74 & 184 & 126 & 68.5 \\
Effluent 3 & 3.5 & 80 & 145 & 82 & 56.6 \\
Effluent 4 & 2.3 & 89 & 76 & 29 & 38.2 \\
\hline
\end{tabular}




\subsection{Analytical methods}

The gas oil feed and the four hydrotreated effluents were analyzed by FT-ICR/MS with the LTQ-FT Ultra (ThermoFisher Scientific, Bremen, Germany) equipped with a 7T magnet ${ }^{48-51}$. In order to be selective for nitrogen compounds, the Electrospray ionization (ESI) technique was used. The ionization was performed at atmospheric pressure, in liquid phase. Mild ion transfer conditions (low voltages) were chosen so as to avoid fragmentation of the ions. ESI was performed in two modes. The positive mode Electrospray Ionization (ESI (+)) was utilized in order to analyze basic nitrogen compounds. $1 \mu \mathrm{L}$ of sample was diluted by $999 \mu \mathrm{L}$ of a mixture of toluene and methanol (50/50 vol \%) with $1 \mu \mathrm{L}$ of formic acid. Neutral nitrogen compounds were ionized by negative mode Electrospray (ESI (-)). $1 \mu \mathrm{L}$ of sample was diluted by $999 \mu \mathrm{L}$ of a mixture composed by toluene and methanol (50/50 vol \%) and $1 \mu \mathrm{L}$ of $\mathrm{NH}_{3}$ was added to the diluted sample in order to enhance the ionization process. In the two modes, the instrument settings of each analysis had to be optimized in order to obtain a good distribution (high peak intensity and selective ionization of $\mathrm{N}_{1}$-type compounds). The data acquisition was performed for an $\mathrm{m} / \mathrm{z}$ ratio range of $98-1000$, with a resolution of 100.000 and 64 microscans were acquired by sample.

Due to the complexity of component matrix, the information ( $\mathrm{m} / \mathrm{z}$ ratio) obtained from FT/ICR-MS spectra was structured according to the concept proposed by Kendrick ${ }^{52}$, which is based on the repetition of $\mathrm{CH}_{2}$ groups (mass $=14.01565 \mathrm{u}$ ). With Kendrick's concept, nitrogen compounds are classified as a function of their alkylation degree (associated to ion mass) and of the degree of unsaturation (associated to Kendrick Mass Defect) ${ }^{26}$. Compounds having the same value of Kendrick Mass Defect will show the same degree of unsaturation (DBE), the same number of heteroelements, of aromatic cycles, or the same number of double bonds, but a different number of carbon atoms distributions ${ }^{53}$.

A drawback of the FT-ICR/MS technique is that the ionization efficiency may vary from one nitrogen compound to another. Moreover, basic and neutral nitrogen species are not analyzed under the same ionization conditions. For a semi-quantitative interpretation, we made the following assumptions: (i) We assumed that each basic compound had the same ionization efficiency in $\mathrm{ESI}(+)$ mode (and each neutral compound in $\mathrm{ESI}(-)$ mode); (ii) The pseudo concentration of basic molecules was calculated by the product of its relative peak intensity in the $\mathrm{ESI}(+)-\mathrm{FT}-\mathrm{ICR} / \mathrm{MS}$ spectra and of the basic nitrogen content (in 
case of FT-ICR/MS). The pseudo concentration of neutral molecules was calculated by the product of its relative intensity in the ESI(-)-FT-ICR/MS spectra and of the neutral nitrogen content.

$\mathrm{C}_{\text {basic, } \mathrm{DBE}, \mathrm{CN}}=$ Relative Intensity $\mathrm{ESI}(+) \mathrm{FTICR} / \mathrm{MS}_{\mathrm{DBE}, \mathrm{CN}} \bullet$ Total basic nitrogen $(\mathrm{ppm})$

$\mathrm{C}_{\text {neutral, DBE, CN }}=$ Relative Intensity ESI(-)FTICR/MS $\mathrm{DBE}, \mathrm{CN}_{\bullet} \bullet$ (Total nitrogen - Total basic nitrogen) (ppm)

In order to validate the semi-quantitative character of this method, the composition of the gas oil feed obtained by FT-ICR/MS analysis was compared to quantitative GCxGC-NCD analysis following IFP 0612. This method was previously described ${ }^{16}$.

Moreover, in order to evaluate the change of saturated/aromatic compositions and the conversion by cracking reactions of the gas oil feed after hydrotreatment, the gas oil feed and the hydrotreated effluent at $80 \%$ of HDN conversion were analyzed by comprehensive high-temperature two-dimensional chromatography coupled with simulated distillation. This method was well described in a previous work ${ }^{54}$ and the set-up was reported in supporting information.

\section{Results}

\subsection{Characterization of the gas oil feed by FT-ICR/MS: Semi-quantification comparison with GCxGC-NCD}

FT-ICR/MS data showed that so-called N1 species were the most abundant ( $78 \%$ of the total intensity in the basic class and $68 \%$ of the total intensity in the neutral class), compared to other polyheteroatom families. This result is coherent with other FT-ICR/MS studies of CGOs ${ }^{29,32,55}$.

Figure 3 shows the distribution of basic $N_{1}$ compounds and neutral $N_{1}$ compounds by carbon number and DBE. These compounds were mainly found in the $\mathrm{m} / \mathrm{z}$ range of $150-450$, on both basic and neutral classes.

In the basic class, compounds with $\mathrm{DBE}=7-9$, which are most likely derivatives of quinoline are the most abundant species. In line with our result, $\mathrm{Li}$ and $\mathrm{Liu}^{55}$ also reported that $\mathrm{DBE}=7,8$ compounds were the 
dominating basic species in the $400^{\circ} \mathrm{C}-425^{\circ} \mathrm{C}$ fraction distilled of Liaohe coker gas oil. The carbon number of nitrogen basic compounds in our feed was in the range of $\mathrm{C} 12-\mathrm{C} 30$ (the center found at $\mathrm{C} 16-\mathrm{C} 24$ ). The basic compounds in our feed were less alkylated than in CGOs reported in literature ${ }^{31,55,56}$, since our feed was lighter (c.f. the boiling point range in Table 1).
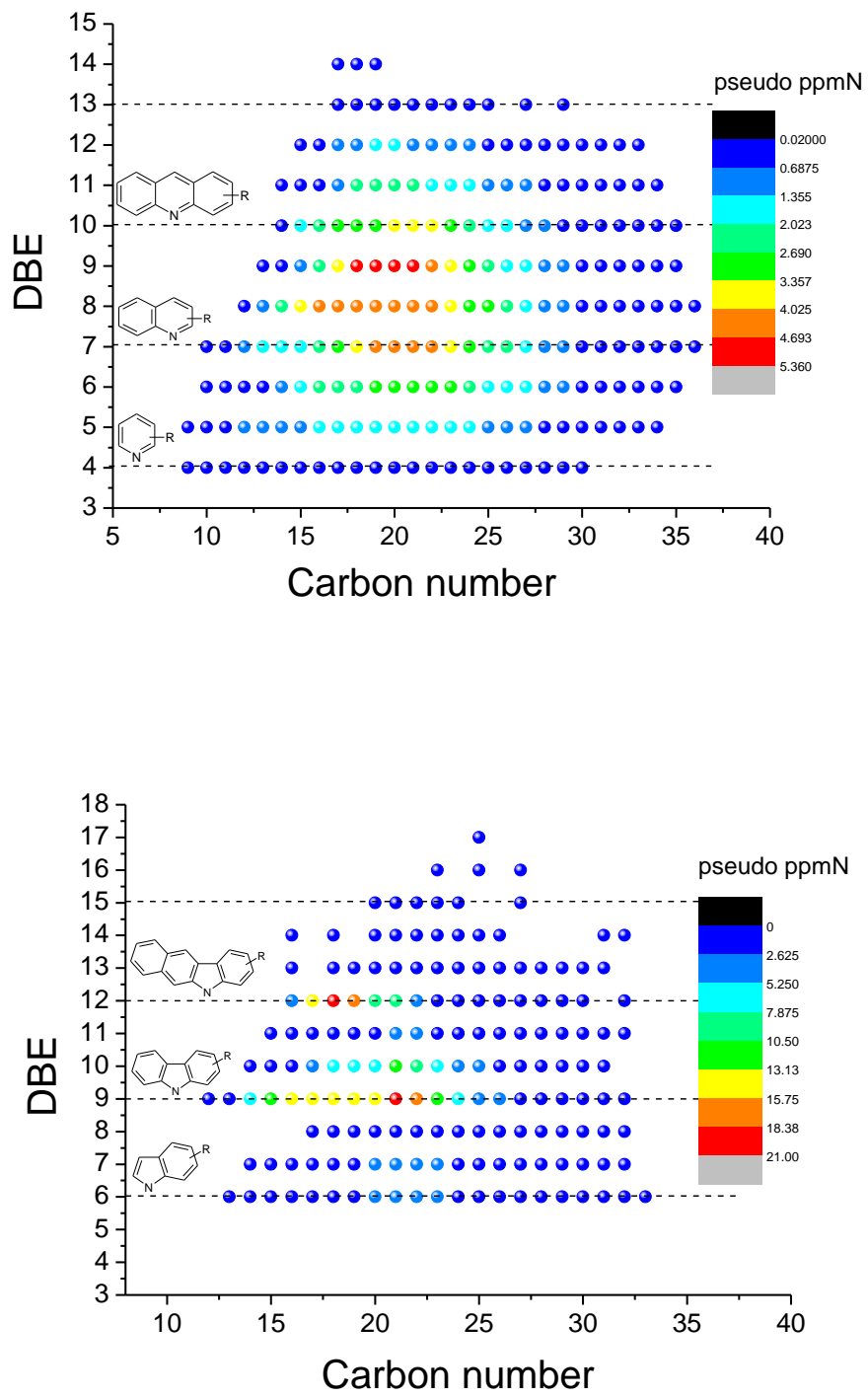

Figure 3 : Distribution of basic N1 compounds (a) and neutral N1 compounds (b) by DBE and carbon number in the gas oil mixture.

In the neutral class, alkyl-carbazoles $(\mathrm{DBE}=9$ ) and alkyl-benzocarbazoles (DBE $=12$ ) were the most abundant whereas compounds with $\mathrm{DBE}=10,11$, which are likely naphteno-carbazoles, were found with 
significantly lower intensity. The center of carbon number distribution was in the range of $18-22$ carbon atoms. Most of benzocarbazole compounds in the feed were found to have 18 carbon atoms, whereas most of indole and carbazole type compounds had 21 carbon atoms. The distribution of DBE and carbon number of neutral nitrogen species of our feed is in agreement with the data obtained by Zhu et al. ${ }^{32}$ for heavy CGOs, in which derivatives of carbazole and benzocarbazole with 17-22 carbon atoms were found as the most abundant compounds. Moreover, Chen et al. ${ }^{27}$ found that benzocarbazoles (DBE $\left.=12\right)$ were the most abundant in Shengli coker gas oil, which was slightly heavier than our feed (i.e. its boiling point at $90 \%$ point in simulation distillation was $417^{\circ} \mathrm{C}$ against $381^{\circ} \mathrm{C}$ in our feed).

The gas oil feed was also analyzed by GCxGC-NCD. GCxGC-NCD is more quantitative than FT-ICR/MS, but due to the partial overlap of compounds such as alkyl-pyridines with alkyl-quinolines and alkylcarbazole with alkyl-benzocarbazole, the GCxGC-NCD technique did not allow distinguishing these families in detail (as FT-ICR/MS does). Despite this shortcoming, the quantification of basic N-compounds (alkyl derivatives of quinoline, pyridine, aniline, tetrahydroquinoline and acridine) by GCxGC-NCD indicated that these compounds represented about $44 \%$ of the total $\mathrm{N}$-compounds. This was consistent with the titration analysis, which measured $41 \%$ of basic nitrogen in the gas oil feed (Table 1 ).

The results of GCxGC-NCD and FT-ICR/MS analyses were compared in Figure 4. For comparison, DBEbased families were regrouped by their position on the GCxGC-NCD chromatogram. For instance, in the neutral class, carbazole and benzocarbazole-type compounds (Group 5) were combined because the GCxGC-NCD did not allow the separation of these compounds. Tetrahydrocarbazole and octahydrocarbazole type compounds were combined with alkyl-indole (Group 4) as we considered a similar polarity of these compounds. Similarly, pyridine, aniline, tetrahydroquinoline and octahydroacridine type compounds were grouped together (Group 1: DBE $=4,5,6$ ). 

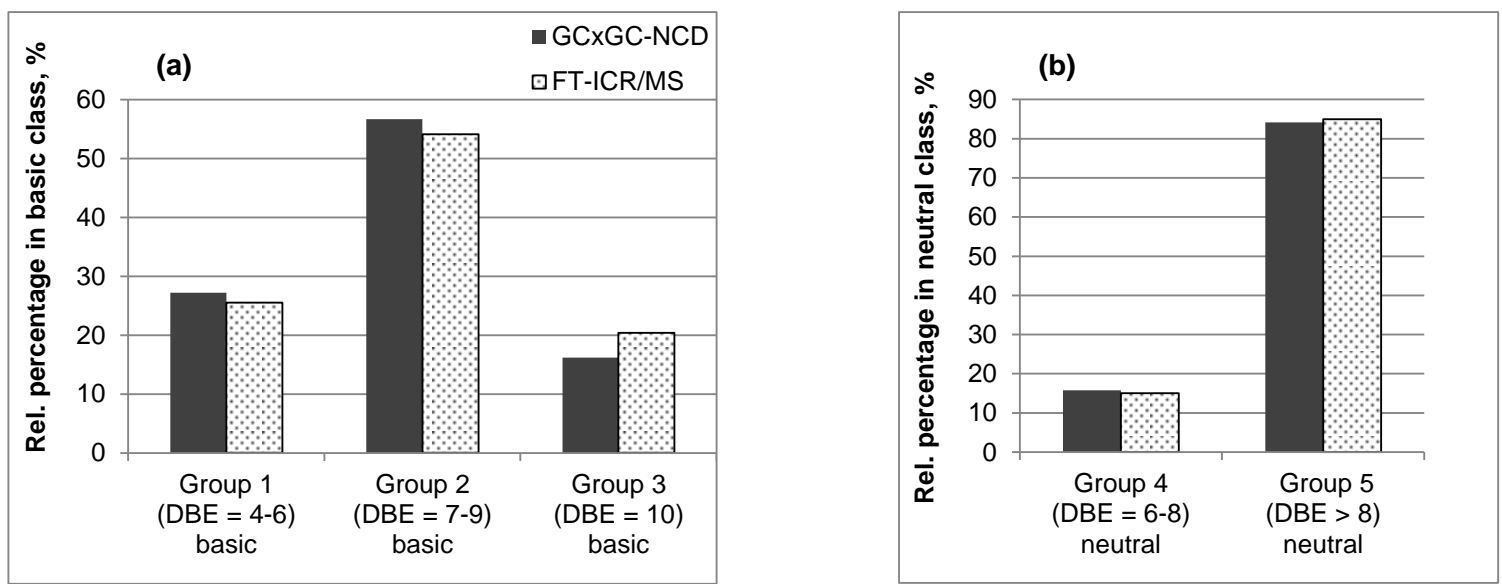

Figure 4: Relative abundances of nitrogen compound groups of the gas oil feed by GCxGC-NCD and FTICR/MS. Results are showed in relative percentage of each grouped family in basic (a) and neutral (b) classes (to which it belongs). In this figure: in basic class: Group 1 (DBE = 4-6): Pyridines, Anilines, Tetrahydroquinolines, Octahydroacridines; Group 2 (DBE=7-9): Quinolines, tetrahydroacridines, octahydrobenzacridines; Group 3 ( $D B E=10)$ : acridines; in neutral class: Group 4 (DBE=6-8): Indoles, tetrahydrocarbazoles, octahydrobenzocarbazoles; Group 5 (DBE>8): carbazoles, benzocarbazoles.

The FT-ICR/MS results were in a good coherence with GCxGC-NCD results. The most abundant nitrogen compounds were also identified by both techniques: alkyl-quinolines and alkyl-(benz)acridines for the basic class and alkyl-carbazole and alkyl-benzocarbazole in the neutral class. This confirmed that FTICR/MS technique was suitable for semi-quantification in our study. Moreover, as compared to GCxGCNCD, the FT-ICR/MS technique provided the advantage of a more detailed distinction of compounds by DBE and carbon number.

\subsection{Conversion of DBE-based basic and neutral families}

As already mentioned before, the FT-ICR/MS analysis of the feed showed that polyheterocompounds were present in significant amounts (up to 20\%), in particular N1S1 and N1O1 compounds. However, under our operating conditions, these compounds were absent in the hydrotreated effluents, i.e. they were converted very quickly (Figure 5). Sulfur-containing rings and oxygen-containing rings are generally more reactive towards hydrotreating than nitrogen-containing rings ${ }^{57}$. Therefore, the $\mathrm{N} 1 \mathrm{~S} 1$ and $\mathrm{N} 1 \mathrm{O} 1$ compounds were supposed to undergo first sulfur and oxygen removal to produce N1 compounds. In the DBE distributions shown in the following figures, the N1S1 and N1O1 classes were, thus, added to the 
corresponding $\mathrm{N} 1$ class. This assumption allows accounting at the same time for the conversion of $\mathrm{N} 1$ and of polyheteroatom compounds. The contribution of N2 compounds was neglected (their behavior is qualitatively similar to that of $\mathrm{N} 1$ compounds, see supporting information).
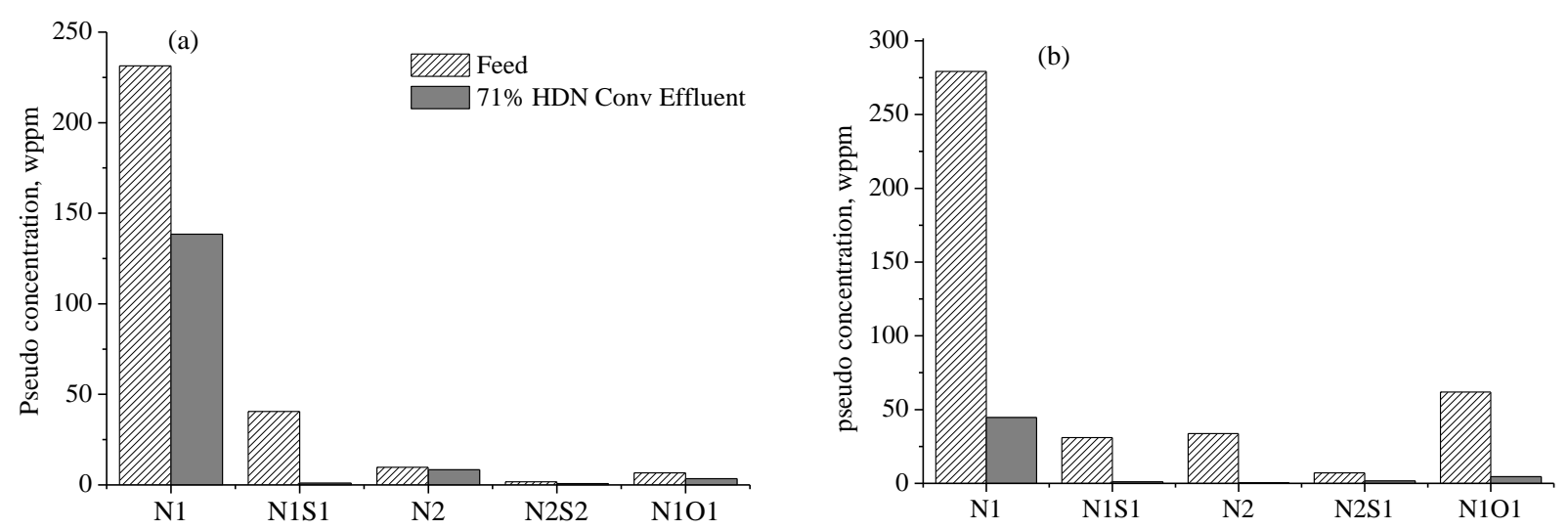

Figure 5: Concentration of different nitrogen-containing heteroatom families in the feed and in the $71 \%$ HDN conversion effluent, for basic class (a) and neutral class (b). Concentration of each family was calculated by using the relative intensity determined from the mass spectra and assuming the same response factor towards ionization capacity of all families.

Figure 6 shows the distribution of basic nitrogen compounds by DBE values of the gas oil feed and the effluents at different HDN conversions. In the hydrotreated effluents, the peak of the DBE distribution of basic compounds shifted from DBE $=8$ to $\mathrm{DBE}=6$. At the lowest HDN rate $(71 \%)$, the concentration of basic $\mathrm{N}$-compounds with $\mathrm{DBE}=4,5,6$ (pyridines, anilines and partially hydrogenated quinolines) was even higher than in the feed. In other words, at intermediate conversions, there was a net formation of these low DBE families, before they were finally consumed at deeper HDN levels. Subsequently, at 8089\% HDN conversion, the distribution shifted to higher DBE values, but the most abundant DBEs remained lower than 8 . The major basic $\mathrm{N}$-compounds that were left over at the highest HDN conversion level ranged from quinolines $(\mathrm{DBE}=5)$ to octahydrobenzacridines $(\mathrm{DBE}=9)$. 


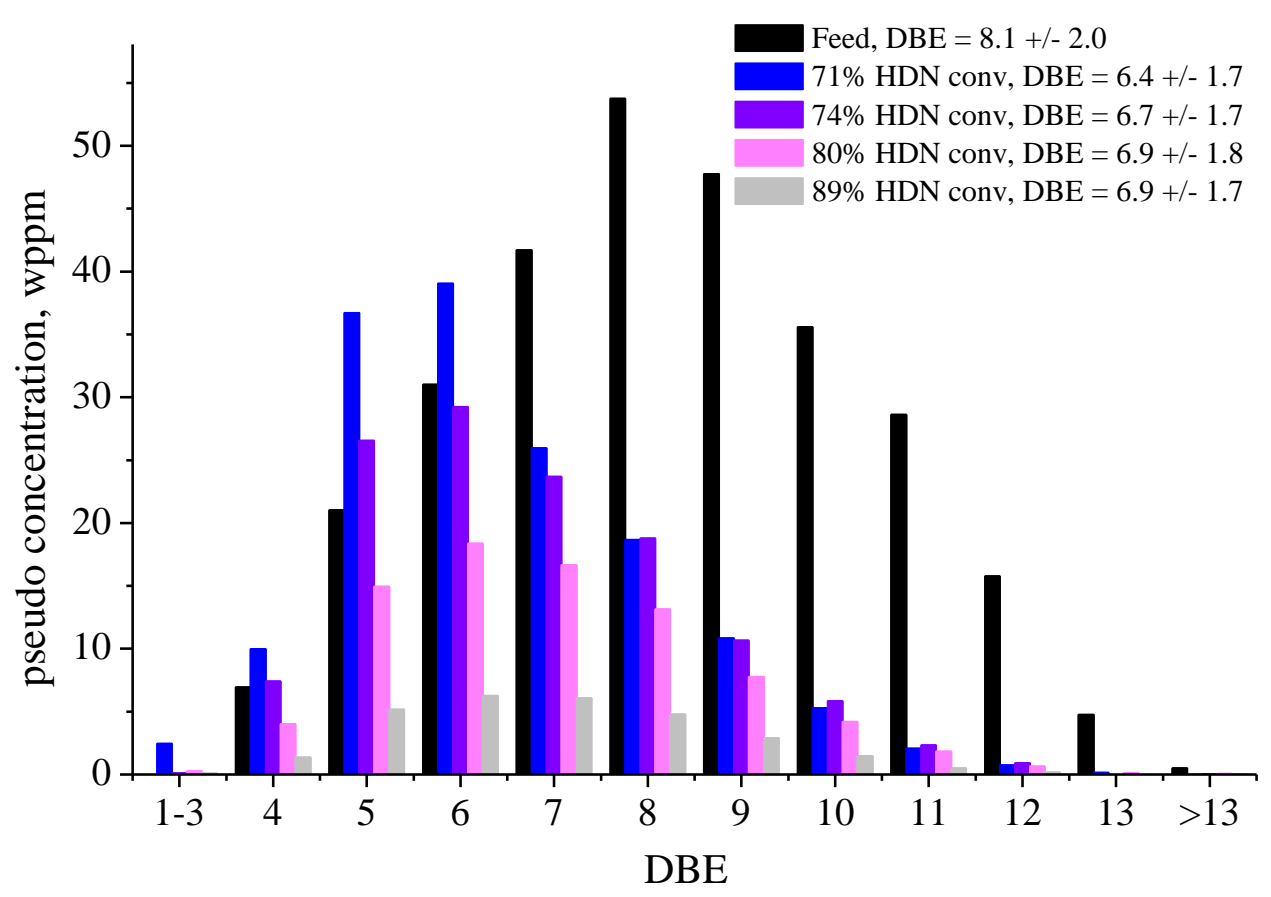

Figure 6: Pseudo concentration of each basic DBE-based family in the gas oil feed and the effluents from the catalytic tests at different HDN conversion. For each $D B E, H D N$ conversion gradually increases from left to right. The $D B E$ values could represent the corresponding mono-atom nitrogen containing families: 1-3 (Amines), 4 (Pyridines, Anilines), 5 (tetrahydroquinolines), 6 (octahydroacridines), 7 (quinolines), 8 (tetrahydroacridines), 9 (octahydro-benzacridines), 10 (acridines), 11 (tetrahydro-benzacridines), 12 (octahydro-dibenzacridines), 13 (benzacridines). $N_{1} S_{1}$ and $N_{1} O_{1}$ families were included in the $N_{1}$ family. Values of DBE next to the legends are the weighted arithmetic mean DBEs and the dispersion of DBE around the average value.

Similarly, from ESI (-)-FT/ICR-MS analysis, we were able to calculate the pseudo concentration of the DBE-based neutral nitrogen families (Figure 7). As already pointed out in our kinetic study, that was published elsewhere, the neutral compounds behaved in a very different way from the basic ones. At $71 \%$ HDN conversion, the concentration of all neutral compounds was already strongly reduced. Only a small concentration carbazoles $(\mathrm{DBE}=9)$ and tetrahydrobenzocarbazoles $(\mathrm{DBE}=10)$ were left over. When increasing the HDN conversion further, the concentration of these neutral families was almost unchanged. We are confronted with two extreme behaviors: the majority of the neutral compounds were converted very quickly, but a small fraction was extremely refractory to HDN conversion. 


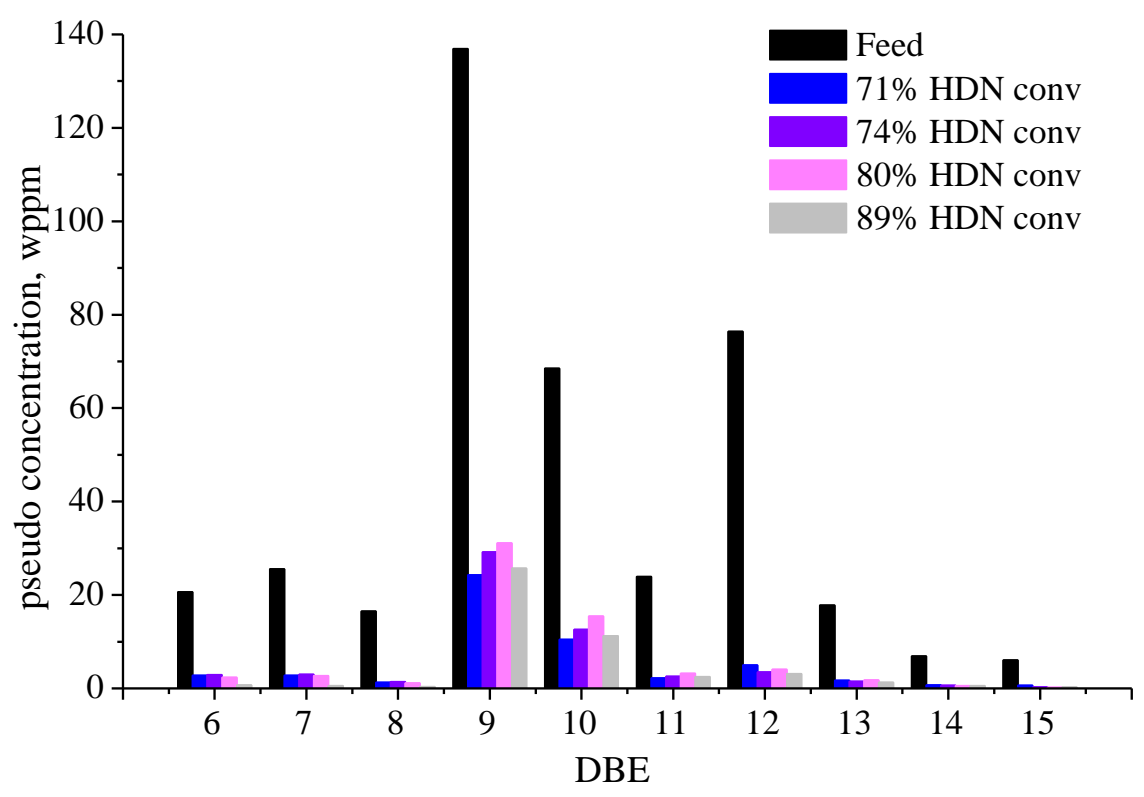

Figure 7: Pseudo concentration of each neutral DBE-based family in the gas oil feed and the effluents from the catalytic tests at different $H D N$ conversion. For each $D B E, H D N$ conversion gradually increases from left to right. The DBE values could represent the corresponding mono-atom nitrogen containing families: 6 (Indoles), 7 (tetrahydro-carbazoles), 8 (octahydro-benzocarbazoles), 9 (carbazoles), 10 (tetrahydro-benzocarbazoles), 11 (octahydro-dibenzocarbazoles), 12 (dibenzocarbazoles), 13 (tetrahydrodibenzocarbazoles). $N_{1} S_{1}$ and $N_{1} O_{1}$ families are included in the $N_{1}$ family.

\subsection{Carbon number distribution}

We will now analyze the carbon number distribution of nitrogen species in the hydrotreated effluents. In theory, the carbon number distribution could be modified by two factors: (i) if more alkylated (heavier) nitrogen species react faster than the less alkylated (lighter) one, the carbon number distribution will shift to lighter products and vice versa; (ii) if cracking of alkyl chains takes place before HDN conversion, the carbon number distribution will also shift to lighter products.

Figure 8 shows the experimental carbon number distributions extracted from summing up the $\mathrm{ESI}(+)$ and ESI(-) FT-ICR/MS data. The maximum and the arithmetic mean of the carbon number distribution shifted to a lower carbon number (compared to the feed) at $71 \%$ HDN conversion. The shift was mainly caused by the formation of basic nitrogen species with low molecular weight. When further pushing the HDN conversion, the carbon number distribution shifted back to higher carbon numbers. The lowest carbon number that was detected in significant amount was always 10 (with traces of C8 and C9 in some of the 
effluents). At $71 \%$ HDN conversion, the concentration of C10 to $\mathrm{C} 12$ slightly exceeded the concentration in the feed (mainly due to the net formation of basic compounds in this carbon number range), which could indicate that cracking reactions took place. However, due to the semi-quantitative nature of the method we cannot be affirmative about this conclusion.

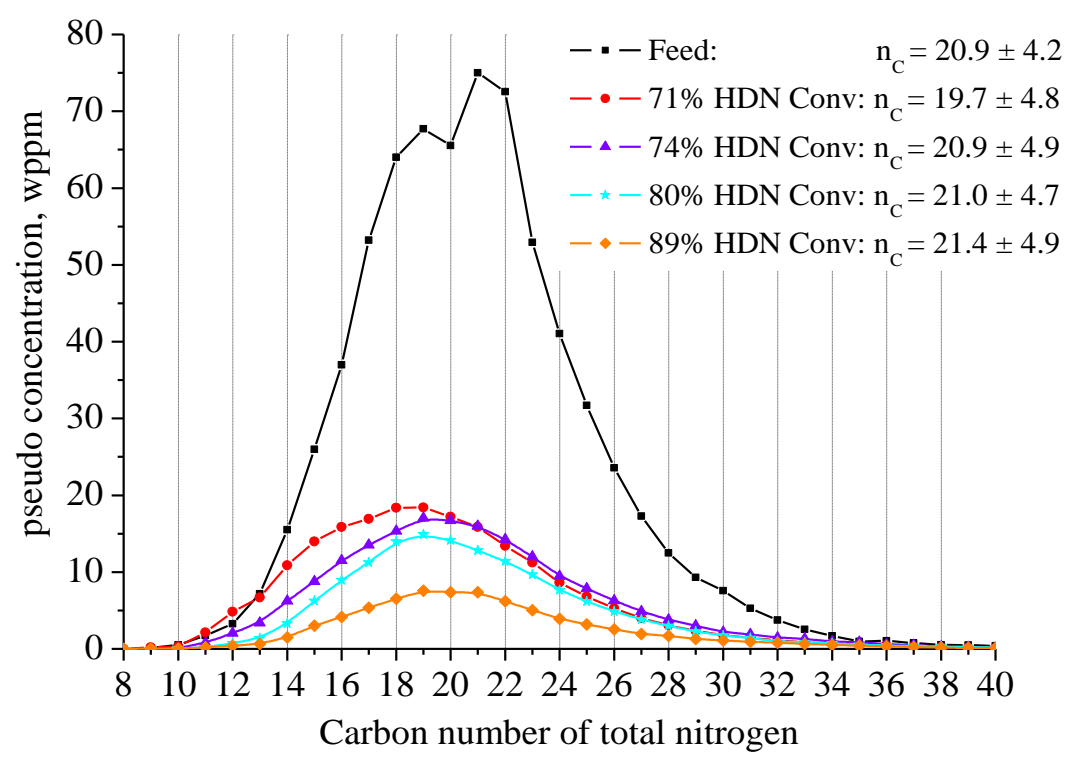

Figure 8: Carbon number distribution curves of total nitrogen in the effluents and in the feed. Values of $n_{C}$ next to the legends are the first moment or weighted arithmetic mean carbon numbers and the dispersion of carbon number around the average carbon number. The calculation of the first moment and the dispersion is given in the supplementary information.

Further investigation of the carbon number distribution of each DBE-based basic family (Figure 9) showed that each family exhibits a very different evolution as a function of HDN conversion. For nitrogen compounds with DBEs equal to or lower than 7 (e.g. less condensed than quinoline), their carbon number shifted to lower values in the effluents as compared to the feed. The shift was the most remarkable at the lowest HDN conversion (71\%) and for the lowest DBE families (pyridines and anilines). Remember that the concentration of the DBE-families 4, 5 and 6 exceeded the concentration in the feed at moderate HDN conversion. The carbon number distribution of these three families shows that the increase was mainly due to the formation of light products with a carbon number between 12 and 16, whereas heavy compounds (above carbon number of 20) were consumed with respect to the feed. For nitrogen compounds with higher DBE values (7 and above), no net formation of light products was observed in our 
effluents. At DBE values above 8, the carbon number distribution in all the effluents tended to shift to higher (instead of lower) values. Above $71 \%$ HDN conversion, the carbon number distribution curves of every basic compound gradually shifted to higher carbon numbers with the HDN conversion. This result suggested a difference in HDN reactivity of short and long alkyl-chain nitrogen compounds.

Table 3 shows the evolution of the average DBE of basic nitrogen compounds with different carbon numbers as a function of conversion. The table expresses in a more quantitative manner two observations that were discussed in the previous paragraphs: (i) the shift of the distribution to lower DBE values is a lot more pronounced for light compounds. (ii) When conversion increases, the distribution has a slight tendency to shift back to higher DBE values.

Table 3: The shift of DBE distribution of C15, C20 and C26 basic nitrogen compounds during conversion, represented by the average $D B E$ value with the dispersion around the average value of the $D B E$ distribution.

\begin{tabular}{lccccc}
\hline & Feed & $71 \%$ conv & $74 \%$ conv & $80 \%$ conv & $89 \%$ conv \\
\hline C15 N-compounds & $8.2 \pm 1.9$ & $5.6 \pm 1.1$ & $5.8 \pm 1.1$ & $5.7 \pm 1.1$ & $6.0 \pm 1.5$ \\
\hline C20 N-compounds & $8.6 \pm 2.1$ & $6.8 \pm 1.6$ & $7.0 \pm 1.7$ & $7.0 \pm 1.7$ & $6.8 \pm 1.5$ \\
\hline C26 N-compounds & $8.1 \pm 2.2$ & $7.4 \pm 1.9$ & $7.3 \pm 1.9$ & $7.4 \pm 1.9$ & $7.5 \pm 1.8$ \\
\hline
\end{tabular}
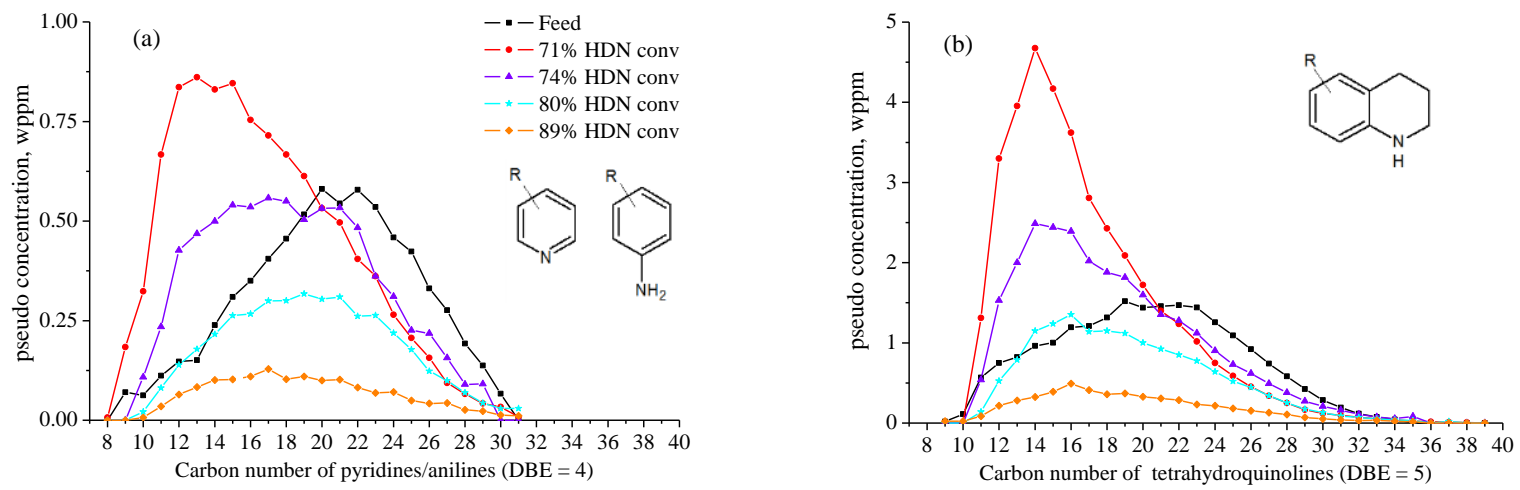

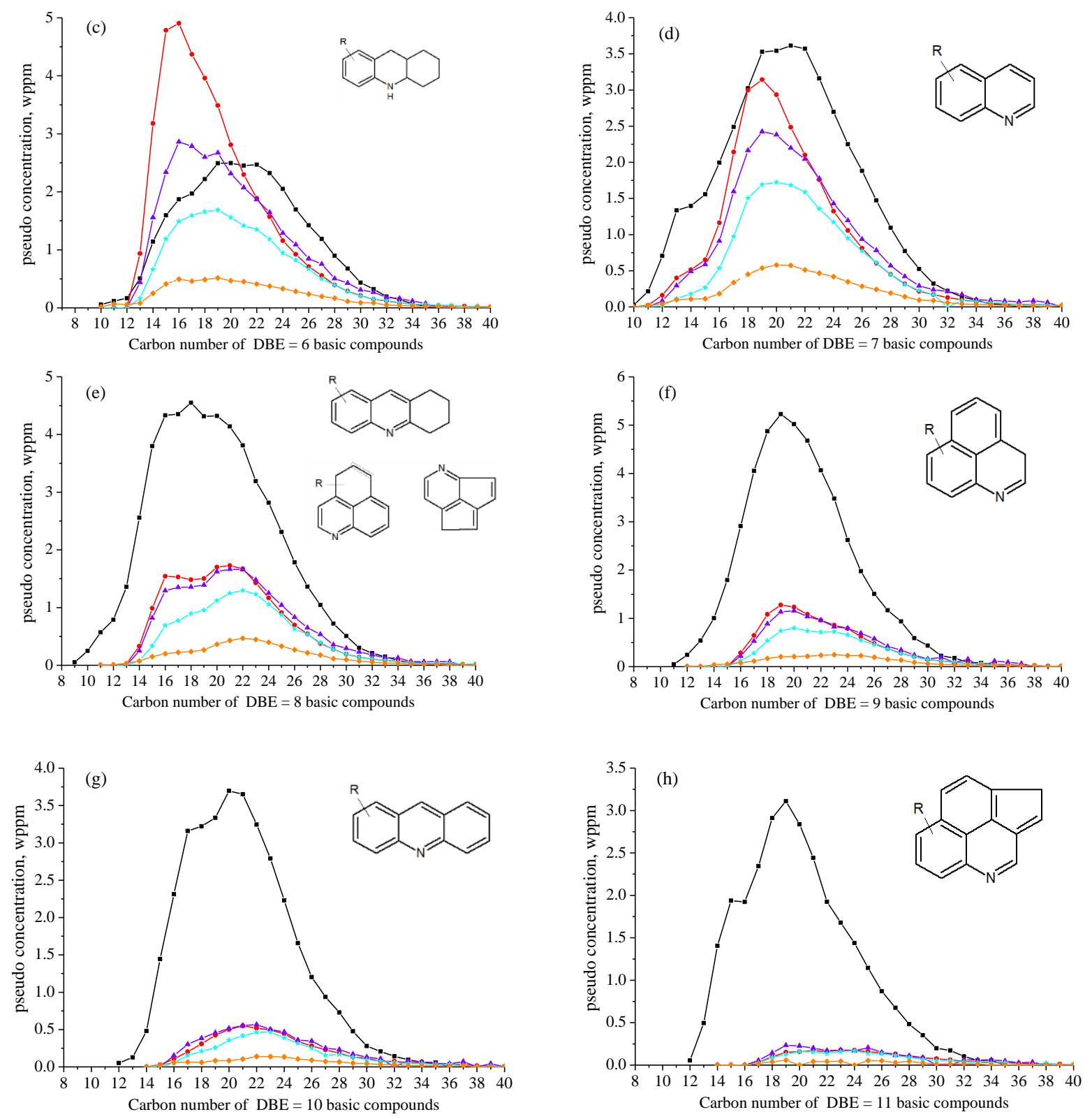

Figure 9: Carbon number distribution curves of every DBE-based basic nitrogen family in the effluents as compared to that in the feed. Molecular structures given for each DBE are representative examples 

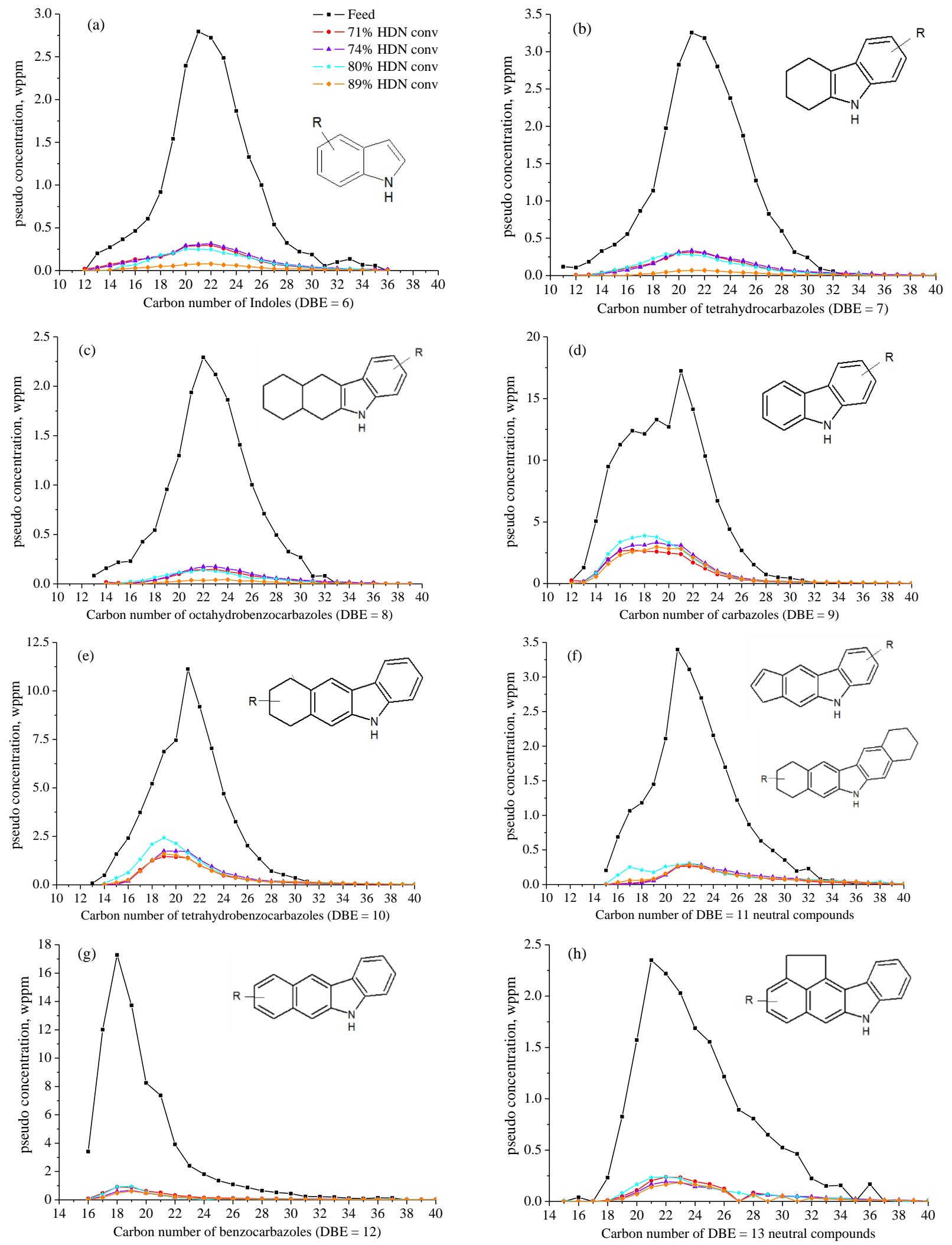

Figure 10: Carbon number distribution curves of every DBE-based neutral nitrogen family in the effluents as compared to that in the feed. Molecular structures given for each DBE are representative examples 
In contrast to the basic compounds, the carbon number distribution of alkyl-indole and alkylbenzocarbazole did not change during HDN conversion (Figure 10). Note, however, that a hydrogenation of the five-membered nitrogen ring of indole derivatives converts these compounds into the basic pool (i.e. the partially hydrogenated intermediates are detected in $\mathrm{ESI}(+)$ mode), which could contribute to the observed modification of the carbon number distribution in that pool. Interestingly, the form of carbon number distribution of alkyl-carbazole $(\mathrm{DBE}=9)$ and alkyl-tetrahydro-benzocarbazole $(\mathrm{DBE}=10)$ changed during HDN conversion, e.g. from a bimodal form in the feed (probably because the feed is a mixture of straight run and coker gas oil) into a monomodal form in the effluents. This suggested the existence of the two families of different HDN reactivity in these compounds which seems to depend on the alkyl substitution of the molecule. The residual neutral compounds at high HDN conversion were carbazoles and benzocarbazoles, mainly with carbon numbers between 17 and 23 .

\subsection{Distillation curves and saturated/composition after hydrotreatment}

Simulated distillation analysis allowed us to determine the boiling point range and to estimate the liquid conversion under this operating condition (Figure 11). At $80 \%$ HDN conversion, the liquid conversion of $250^{\circ} \mathrm{C}+$ cut was about $4 \%$, which is negligible.

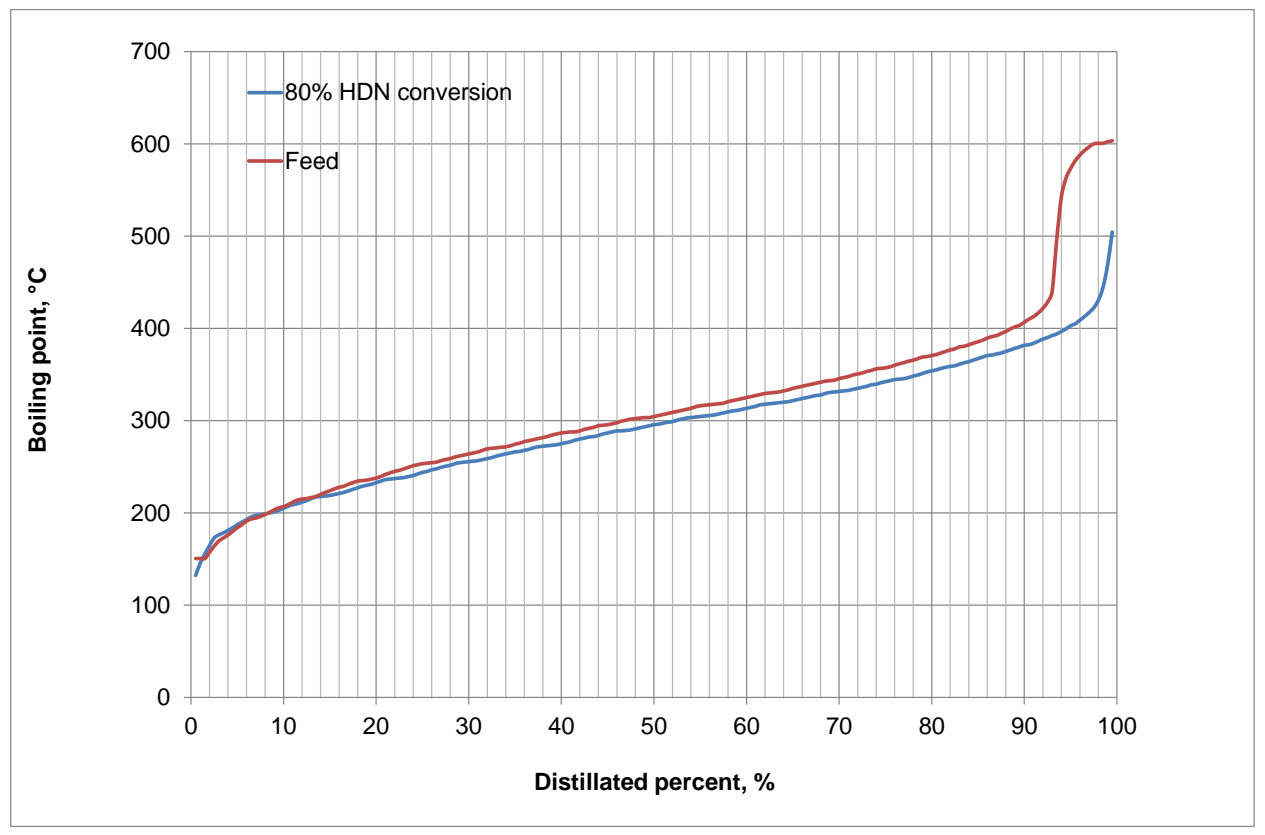

Figure 11 : Simulated distillation curve of the gas oil feed and $80 \%$ HDN conversion effluent 
The shift of simulated distillation curve to lower boiling points was attributed to the hydrogenation of aromatics (tri, di and mono-aromatic compounds) into saturated compounds (paraffin and naphthenic compounds) (Figure 12).

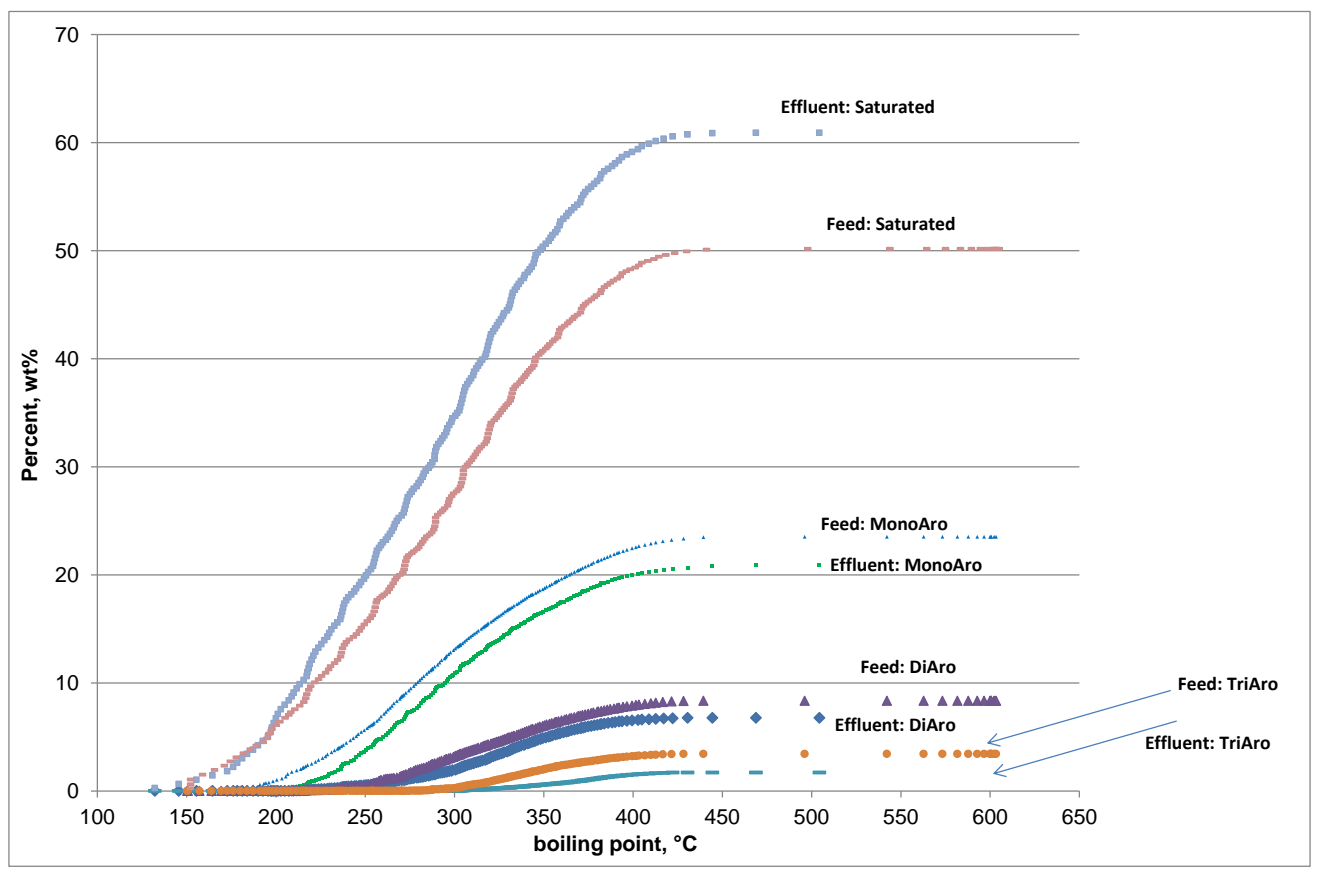

Figure 12: Composition of Saturated and Aromatic compounds of the gas oil feed and $80 \%$ HDN conversion effluent by HT-GCXGC-FID-SimDis analysis

\section{Discussion}

\subsection{Reaction pathway of gas oil hydrodenitrogenation}

Under our experimental conditions, HDN conversion was varied in the range of 70 to $90 \%$ (see Table 2). At the early stages of hydrotreatment, a shift of the DBE distribution of basic nitrogen species to lower values was observed (Figure 6). This shift can be attributed to hydrogenation and ring-opening reactions: alkyl-anilines or pyridines $(\mathrm{DBE}=4)$ were formed by ring opening of tetrahydroquinolines $(\mathrm{DBE}=5)$, tetrahydroquinolines $(\mathrm{DBE}=5)$ were formed by partial hydrogenation of quinolines $(\mathrm{DBE}=7)$, octahydroacridines $(\mathrm{DBE}=6)$ were formed by partial hydrogenation of (tetrahydro)acridine $(\mathrm{DBE}=8,10)$. 
The observation that partially hydrogenated intermediates were detected as abundant intermediates is coherent with the results of model molecule studies: in the conversion of quinoline, for example, tetrahydroquinoline was an abundant intermediate before conversion to HDN products (Figure 2). The same phenomenon was also observed in the hydrotreating of VGO ${ }^{33}$. Still, the observation that nonnegligible residual concentrations of anilines were observed in the effluents even at very high HDN conversions was surprising, since these compounds should be very reactive. The HDN of anilines in the gas oil feed was probably inhibited by other more basic compounds ${ }^{58}$.

For neutral nitrogen compounds, a DBE shift was not observed. In other words, the dominating compounds in the feed, i.e. carbazoles, tetrahydrobenzocarbazoles and benzocarbazoles, were not converted to partially hydrogenated intermediates that could be detected in the ESI(-) mode. Two explanations are possible: either the neutral compounds were directly converted to HDN products without passing by stable partially hydrogenated intermediates, or the hydrogenated intermediates belonged to the basic class (hydrogenation of the pyrrole ring and ring opening to anilines leads to basic compounds). According to the results of model molecules studies, the first explanation seems more likely. In model molecule tests, the HDN conversion of carbazole is very close to its overall conversion ${ }^{11,12,43}$. However, we will show evidence that a certain fraction of the neutral compounds may be converted to the basic class (see section 4.4).

\subsection{Why does the conversion of neutral compounds stagnate at deep HDN levels?}

The behavior of basic and neutral nitrogen compounds as function of HDN conversion was very different (Table 2). Basic nitrogen species were very gradually converted, whereas the neutral species disappeared very quickly at low conversion, but subsequently their concentration remained constant ${ }^{45}$. This behavior applies to the N1, but also to the N2 class. Our results confirm the paradigm that carbazole species are the most refractory nitrogen compounds ${ }^{59}$ but the refractory character only appears at rather high conversions. At the early stages of the reaction, the neutral nitrogen species were even more reactive than the basic compounds. How can we explain the abrupt change in reactivity of the neutral nitrogen compounds between the initial and the final stage of the reaction? A possible explanation would be that 
the compounds which are converted at the early and at the final stage differ in their degree of alkylation (i.e. in molecular weight). However, a look at the carbon number distributions of the $\mathrm{DBE}=9$ and 10 compounds shows that they are not strongly modified between feed and effluent (apart from the fact that the second peak in the bimodal distribution has disappeared). Hence, the reactivity of the carbazoles and tetrahydrobenzocarbazoles in the feed does not seem to depend strongly on the total length of the alkyl substituents. A dependence of reactivity on the position of the alkyl substituents was reported in the literature ${ }^{1,59}$ but our analysis methods is not sensitive to the position of alkyl groups or the type of alkyl substitution (hexamethyl vs. hexyl, for example). Therefore, we cannot substantiate this hypothesis. Ion mobility data or GCxGC HRMS would be needed to explore a possible impact of steric hindrance ${ }^{14,60,61}$.

It was also suggested that the refractory character of carbazole compounds is not due to a low intrinsic activity of these compounds, but to a strong inhibition by basic nitrogen species, which are present in the

reaction mixture ${ }^{11}$. This is certainly a reasonable hypothesis, since it is well known that the inhibition effect of nitrogen species is strongly correlated to their basicity ${ }^{43,62}$. In model molecule tests, we recently demonstrated the strong inhibiting effect of quinoline on the conversion of indole. For the case of our gasoil mixture, the question arises why the strong inhibition effect only comes after a certain conversion level. Our tentative explanation goes as follows: the partially hydrogenated quinoline and acridine compounds, which were detected in the $\mathrm{ESI}(+)$ mode (see previous section) are more basic and therefore have a stronger inhibition effect than the aromatic pyridine rings in the feed. The relative inhibition by basic compounds will, therefore, tend to increase with conversion and in fine block the conversion of neutral species that were not yet converted. As mentioned before, we cannot rule out (nor prove, due to the limitations of our technique) that the position of alkyl substituents on the carbazole structure contributes to the phenomenon.

\subsection{Contribution of cracking reactions}

Cracking reactions and/or a dependence of HDN reactivity on the carbon-number would change the carbon number distribution of $\mathrm{N}$-compounds. Cracking reactions are favored by acid sites of catalyst which are inhibited by nitrogen compounds, especially basic compounds. Thus, cracking should become more pronounced at high HDN conversions. However, the carbon number distribution slightly shifted to lower 
values at $70 \%$ HDN conversion and then shifted back to higher carbon numbers at high HDN conversion (Figure 9). Moreover, the result of comprehensive chromatography coupled with simulated distillation analyses (section 3.4) revealed that cracking reactions are negligible. We, therefore, believe that cracking (dealkylation of cyclic compounds) did not play a significant role in the reaction scheme. The shift in the carbon number distribution has different reasons, as will be explained in the following section.

\subsection{Changes in the carbon number distribution}

The carbon number distribution of each DBE-based family (Figure 9), showed that the shift to low DBE compounds (DBE $=4$ to 6 ) at $~ 70 \%$ HDN conversion was not evenly distributed over all carbon numbers, but concentrated on light products. The accumulation of light, low DBE products led to the downshift of the global carbon number distribution that was observed in Figure 8 . Figure 9 shows that at $\sim 70 \%$ HDN conversion there was a net production (i) of anilines and pyridines, which peaked at C13, (ii) of tetrahydroquinoline, which peaked at $\mathrm{C} 14$, (iii) and of octahydroacridines, which peaked at $\mathrm{C} 16$. The net production of the anilines can be explained by ring opening of tetrahydroquinolines with corresponding carbon numbers. Likewise, the net production of light octahydroacridines corresponded roughly to the disappearance of light tetrahydroacridines, i.e. the former were probably generated by hydrogenation of the latter. However, the significant net production of light tetrahydroquinolines $(\mathrm{DBE}=5)$ cannot be explained by hydrogenation of the corresponding quinolines. We, therefore, presume that some of the light $\mathrm{DBE}=5$ compounds were cyclohexyl-aniline structures (Figure 13), which were generated by ring opening of hexahydro-carbazole structures, i.e. issued from the neutral class.

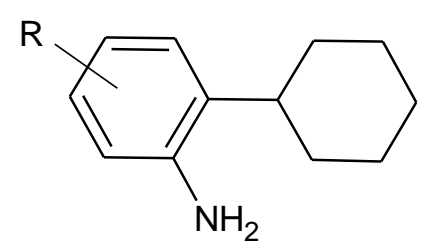

Figure 13 : Basic $D B E=5$ compounds generated from ring opening of hexahydrocarbazole structures The question arises why only low carbon number intermediates accumulated, while such an accumulation of partially hydrogenated heavy products was not observed. Since the low DBE compounds are intermediate products in the reaction network, two explanations are possible. Either the hydrogenation/ring 
opening reactions leading to the low DBE intermediates are faster for compounds with a low degree of alkylation, or the light DBE intermediates, once formed, are transformed less quickly to HDN products. The former explanation seems unlikely. If we look at the carbon number distributions of acridine (a compound, which is only consumed and not formed from other products), we do not observe a preferential conversion of light vs. heavy acridines. We, therefore, believe that the accumulation of light, partially hydrogenated intermediates occurred, because they were transformed less quickly to HDN products than the heavier family members. The reason for this may be a preferential adsorption of the heavier compounds, which inhibits the conversion of the lighter ones ${ }^{63}$.

\section{Conclusions}

Our paper demonstrates that the FT-ICR/MS technique with ElectroSpray Ionization gives a lot of new insights in the hydrodenitrogenation reactions that occur during the hydrotreating of a straight run/coker gas oil. We could show that the basic compounds were first converted to partially hydrogenated intermediates, which then slowly underwent $\mathrm{C}-\mathrm{N}$ bond breaking. This globally reproduces the behavior that was found in model molecule tests.

Neutral compounds behaved in a different way. In the early stages of the reaction they were very quickly converted to HDN products; no significant amounts of partially hydrogenated neutral intermediates were detected (although a closer analysis of the carbon number distributions showed that a fraction of the neutral compounds was converted to basic intermediates).

Under our operating conditions, above $75 \%$ HDN conversion, the conversion of neutral compounds was blocked by stronger competitive adsorption of partially hydrogenated basic nitrogen species. Alkyl derivatives of partially hydrogenated quinolines and acridines remained as refractory compounds in the basic class, while alkyl derivatives of carbazole and tetrahydro-benzocarbazole were the most refractory in the neutral class, at high HDN conversion.

Under our reaction conditions $\left(360^{\circ} \mathrm{C}\right)$, cracking of alkyl chains of nitrogen compounds was assumed to be negligible since the carbon number distribution of total nitrogen was almost unchanged with HDN conversion. An interesting finding of this work was the accumulation of light anilines, pyridines, 
tetrahydroquinolines and octahydroacridines at medium HDN conversion. Our interpretation of this result is that the light intermediate were converted less quickly to the final HDN products than the heavy family members because of preferential adsorption of the latter. For a more quantitative interpretation of the results, kinetic modelling would be needed. This will be the subject of future research.

\section{Acknowledgement}

This work was financially supported by IFP Energies Nouvelles and CNRS, France. The authors are grateful to Chantal LORENTZ (IRCELYON), Lyes ASSAM and Jérôme CAPUANO (IFP Energies Nouvelles) for their helps in analytical experiments.

Supporting information. GCxGC analysis of the effluent, raw FT-ICR/MS spectra in ESI(+) and ESI(-) mode, distribution of polyheteroatom families in the effluents.

\section{Nomenclature}

ASA: amorphous silica alumina

HDN: hydrodenitrogenation

GC-NCD: Gas Chromatography coupled to Nitrogen Chemiluminescence detector

FT/ICR-MS: Fourier Transform Ion Cyclotron Resonance Mass Spectrometry

CNDC: Carbon number distribution curve

DBE: Double Bond Equivalent 


\section{References}

(1) Sumbogo Murti, S. D.; Yang, H.; Choi, K.-H.; Korai, Y.; Mochida, I. Influences of nitrogen species on the hydrodesulfurization reactivity of a gas oil over sulfide catalysts of variable activity. Applied Catalysis A: General, 2003, 252, 331-346.

(2) Prins, R. Catalytic hydrodenitrogenation. Advances in Catalysis, 2001, 46, 399-464.

(3) Sau, M.; Basak, K.; Manna, U.; Santra, M.; Verma, R. P. Effects of organic nitrogen compounds on hydrotreating and hydrocracking reactions. Catalysis Today, 2005, 109, 112-119.

(4) Furimsky, E. Deactivation of hydroprocessing catalysts. Catalysis Today, 1999, 52, 381-495.

(5) Peng, C.; Guo, R.; Fang, X.-c. Improving Ultra-Deep Desulfurization Efficiency by Catalyst Stacking Technology. Catalysis Letters, 2016, 146, 701-709.

(6) Ho, T. C.; Qiao, L. Competitive adsorption of nitrogen species in HDS: Kinetic characterization of hydrogenation and hydrogenolysis sites. Journal of Catalysis, 2010, 269, 291-301.

(7) Satterfield, C. N.; Cocchetto, J. F. Reaction network and kinetics of the vapor-phase catalytic hydrodenitrogenation of quinoline. Ind. Eng. Chem. Proc. Des. Dev. 1981, 20, 53-62.

(8) JIAN, M.; PRINS, R. Mechanism of the Hydrodenitrogenation of Quinoline over $\mathrm{NiMo}(\mathrm{P}) / \mathrm{Al} 2 \mathrm{O}$ Catalysts. Journal of Catalysis, 1998, 179, 18-27.

(9) Nguyen, M.-T.; Tayakout-Fayolle, M.; Chainet, F.; Pirngruber, G. D.; Geantet, C. Use of kinetic modeling for investigating support acidity effects of NiMo sulfide catalysts on quinoline hydrodenitrogenation. Applied Catalysis A: General, 2017, 530, 132-144.

(10) Nguyen, M.-T.; Tayakout-Fayolle, M.; Pirngruber, G. D.; Chainet, F.; Geantet, C. Kinetic Modeling of Quinoline Hydrodenitrogenation over a NiMo(P)/Al $\mathrm{O}_{3}$ Catalyst in a Batch Reactor. Ind. Eng. Chem. Res. 2015, 54, 9278-9288.

(11) Rabarihoela-Rakotovao, V.; Diehl, F.; Brunet, S. Deep HDS of Diesel Fuel: Inhibiting Effect of Nitrogen Compounds on the Transformation of the Refractory 4,6-Dimethyldibenzothiophene Over a $\mathrm{NiMoP} / \mathrm{Al}_{2} \mathrm{O}_{3}$ Catalyst. Catalysis Letters, 2009, 129, 50-60.

(12) Nagai, M.; Masunaga, T.; Hanaoka, N. Hydrodenitrogenation of carbazole on a molybdenum/alumina catalyst. Effects of sulfiding and sulfur compounds. Energy Fuels, 1988, 2, 645-651. 
(13) Cortes, H. J.; Winniford, B.; Luong, J.; Pursch, M. Comprehensive two dimensional gas chromatography review. Journal of separation science, 2009, 32, 883-904.

(14) Mühlen, C. von; Oliveira, E. C. de; Zini, C. A.; Caramão, E. B.; Marriott, P. J. Characterization of Nitrogen-Containing Compounds in Heavy Gas Oil Petroleum Fractions Using Comprehensive TwoDimensional Gas Chromatography Coupled to Time-of-Flight Mass Spectrometry. Energy Fuels, 2010, 24, 3572-3580.

(15) Yan, X. Sulfur and nitrogen chemiluminescence detection in gas chromatographic analysis. Journal of chromatography. A, 2002, 976, 3-10.

(16) Adam, F.; Bertoncini, F.; Brodusch, N.; Durand, E.; Thiébaut, D.; Espinat, D.; Hennion, M.-C. New benchmark for basic and neutral nitrogen compounds speciation in middle distillates using comprehensive two-dimensional gas chromatography. Journal of chromatography. A, 2007, 1148, 55-64.

(17) Chawla, B. Speciation of Nitrogen Compounds in Gasoline and Diesel Range Process Streams by Capillary Column Gas Chromatography with Chemiluminescence Detection. Journal of Chromatographic Science, 1997, 35, 97-104.

(18) Dutriez, T.; Borras, J.; Courtiade, M.; Thiébaut, D.; Dulot, H.; Bertoncini, F.; Hennion, M.-C. Challenge in the speciation of nitrogen-containing compounds in heavy petroleum fractions by high temperature comprehensive two-dimensional gas chromatography. Journal of chromatography. A, 2011, 1218, 3190-3199.

(19) Adam, F.; Bertoncini, F.; Dartiguelongue, C.; Marchand, K.; Thiébaut, D.; Hennion, M.-C. Comprehensive two-dimensional gas chromatography for basic and neutral nitrogen speciation in middle distillates. Fuel, 2009, 88, 938-946.

(20) Dutriez, T.; Courtiade, M.; Ponthus, J.; Thiébaut, D.; Dulot, H.; Hennion, M.-C. Complementarity of Fourier Transform Ion Cyclotron Resonance Mass Spectrometry and high temperature comprehensive two-dimensional gas chromatography for the characterization of resin fractions from vacuum gas oils. Fuel, 2012, 96, 108-119.

(21) van Stee, L. L. P.; Beens, J.; Vreuls, R. J. J.; Brinkman, U. A. T. Comprehensive two-dimensional gas chromatography with atomic emission detection and correlation with mass spectrometric detection: Principles and application in petrochemical analysis. Journal of chromatography. A, 2003, 1019, 89-99. 
(22) Lissitsyna, K.; Huertas, S.; Quintero, L. C.; Polo, L. M. Novel simple method for quantitation of nitrogen compounds in middle distillates using solid phase extraction and comprehensive two-dimensional gas chromatography. Fuel, 2013, 104, 752-757.

(23) Mühlen, C. von; Oliveira, E. C. de; Morrison, P. D.; Zini, C. A.; Caramão, E. B.; Marriott, P. J. Qualitative and quantitative study of nitrogen-containing compounds in heavy gas oil using comprehensive two-dimensional gas chromatography with nitrogen phosphorus detection. Journal of separation science, 2007, 30, 3223-3232.

(24) Qian, K.; Rodgers, R. P.; Hendrickson, C. L.; Emmett, M. R.; Marshall, A. G. Reading Chemical Fine Print: Resolution and Identification of 3000 Nitrogen-Containing Aromatic Compounds from a Single Electrospray Ionization Fourier Transform Ion Cyclotron Resonance Mass Spectrum of Heavy Petroleum Crude Oil. Energy Fuels, 2001, 15, 492-498.

(25) Marshall, A. G.; Rodgers, R. P. Petroleomics: The next grand challenge for chemical analysis. Accounts of Chemical Research, 2004, 37, 53-59.

(26) Cho, Y.; Ahmed, A.; Islam, A.; Kim, S. Developments in FT-ICR MS instrumentation, ionization techniques, and data interpretation methods for petroleomics. Mass spectrometry reviews, 2015, 34, 248263.

(27) Chen, X.; Liu, Y.; Li, S.; Feng, X.; Shan, H.; Yang, C. Structure and Composition Changes of Nitrogen Compounds during the Catalytic Cracking Process and Their Deactivating Effect on Catalysts. Energy Fuels, 2017, 31, 3659-3668.

(28) Shi, Q.; Zhao, S.; Xu, Z.; Chung, K. H.; Zhang, Y.; Xu, C. Distribution of Acids and Neutral Nitrogen Compounds in a Chinese Crude Oil and Its Fractions: Characterized by Negative-Ion Electrospray Ionization Fourier Transform Ion Cyclotron Resonance Mass Spectrometry. Energy Fuels, 2010, 24, 4005-4011.

(29) Xiaobo, C.; Yibin, L.; Jin, W.; Honghong, S.; Chaohe, Y.; Chunyi, L. Characterization of nitrogen compounds in coker gas oil by electrospray ionization Fourier transform ion cyclotron resonance mass spectrometry and Fourier transform infrared spectroscopy. Applied petrochemical research, 2014, 4, 417422. 
(30) Hu, M.; Guo, C.; Zhang, L.; Zhao, S.; Chung, K. H.; Xu, C.; Shi, Q. Petroleum heteroatom compounds in various commercial delayed coking liquids: Characterized by FT-ICR MS and GC techniques. Sci. China Chem., 2017, 60, 284-292.

(31) Shi, Q.; Xu, C.; Zhao, S.; Chung, K. H.; Zhang, Y.; Gao, W. Characterization of Basic Nitrogen Species in Coker Gas Oils by Positive-Ion Electrospray Ionization Fourier Transform Ion Cyclotron Resonance Mass Spectrometry. Energy Fuels, 2010, 24, 563-569.

(32) Zhu, X.; Shi, Q.; Zhang, Y.; Pan, N.; Xu, C.; Chung, K. H.; Zhao, S. Characterization of Nitrogen Compounds in Coker Heavy Gas Oil and Its Subfractions by Liquid Chromatographic Separation Followed by Fourier Transform lon Cyclotron Resonance Mass Spectrometry. Energy Fuels, 2011, 25, 281-287.

(33) Celis-Cornejo, C. M.; Pérez-Martínez, D. J.; Orrego-Ruiz, J. A.; Baldovino-Medrano, V. G. Identification of Refractory Weakly Basic Nitrogen Compounds in a Deeply Hydrotreated Vacuum Gas Oil and Assessment of the Effect of Some Representative Species over the Performance of a Ni-MoS $/ \mathrm{Y}$ Zeolite-Alumina Catalyst in Phenanthrene Hydrocracking. Energy Fuels, 2018, 32, 8715-8726.

(34) Liu, M.; Zhang, L.; Zhao, S.; Zhao, D. Transformation of Nitrogen Compounds through Hydrotreatment of Saudi Arabia Atmospheric Residue and Supercritical Fluid Extraction Subfractions. Energy Fuels, 2016, 30, 740-747.

(35) Liu, D.; Fu, Y.; Deng, W.; Shi, Q.; Ma, K.; Hou, T.; Wu, C. FT-ICR MS Analysis of NitrogenContaining Compounds in the Products of Liaohe Atmospheric Residue Hydrocracking. Energy Fuels, 2011, 26, 624-628.

(36) Chen, X.; Shen, B.; Sun, J.; Wang, C.; Shan, H.; Yang, C.; Li, C. Characterization and Comparison of Nitrogen Compounds in Hydrotreated and Untreated Shale Oil by Electrospray Ionization (ESI) Fourier Transform Ion Cyclotron Resonance Mass Spectrometry (FT-ICR MS). Energy Fuels, 2012, 26, 17071714.

(37) Fu, J.; Klein, G. C.; Smith, D. F.; Kim, S.; Rodgers, R. P.; Hendrickson, C. L.; Marshall, A. G. Comprehensive Compositional Analysis of Hydrotreated and Untreated Nitrogen-Concentrated Fractions from Syncrude Oil by Electron Ionization, Field Desorption Ionization, and Electrospray Ionization Ultrahigh-Resolution FT-ICR Mass Spectrometry. Energy Fuels, 2006, 20, 1235-1241. 
(38) Klein, G. C.; Rodgers, R. P.; Marshall, A. G. Identification of hydrotreatment-resistant heteroatomic species in a crude oil distillation cut by electrospray ionization FT-ICR mass spectrometry. Fuel, 2006, 85, 2071-2080.

(39) Hughey, C. A.; Hendrickson, C. L.; Rodgers, R. P.; Marshall, A. G. Elemental Composition Analysis of Processed and Unprocessed Diesel Fuel by Electrospray Ionization Fourier Transform Ion Cyclotron Resonance Mass Spectrometry. Energy Fuels, 2001, 15, 1186-1193.

(40) Kekäläinen, T.; Pakarinen, J. M. H.; Wickström, K.; Vainiotalo, P. Compositional Study of Polar Species in Untreated and Hydrotreated Gas Oil Samples by Electrospray Ionization Fourier Transform Ion Cyclotron Resonance Mass Spectrometry (ESI FTICR-MS). Energy Fuels, 2009, 23, 6055-6061.

(41) Zhang, T.; Zhang, L.; Zhou, Y.; Wei, Q.; Chung, K. H.; Zhao, S.; Xu, C.; Shi, Q. Transformation of Nitrogen Compounds in Deasphalted Oil Hydrotreating: Characterized by Electrospray lonization Fourier Transform-Ion Cyclotron Resonance Mass Spectrometry. Energy Fuels, 2013, 27, 2952-2959.

(42) Oro, N. E.; Lucy, C. A. Analysis of the Nitrogen Content of Distillate Cut Gas Oils and Treated Heavy Gas Oils Using Normal Phase HPLC, Fraction Collection and Petroleomic FT-ICR MS Data. Energy Fuels, 2012, 27, 35-45.

(43) Nguyen, M.-T.; Pirngruber, G. D.; Chainet, F.; Tayakout-Fayolle, M.; Geantet, C. Indole Hydrodenitrogenation over Alumina and Silica-Alumina-Supported Sulfide Catalysts - Comparison with Quinoline. Ind. Eng. Chem. Res., 2017, 56, 11088-11099.

(44) Nguyen, M. T. PhD Thesis: Support acidity effects of sulfide catalysts in hydrodenitrogenation: From model molecules to gas oil conversions., Université Claude Bernard Lyon 1, 2016.

(45) Nguyen, M.-T.; Pirngruber, G. D.; Albrieux, F.; Chainet, F.; Tayakout-Fayolle, M.; Geantet, C. How Does an Acidic Support Affect the Hydrotreatment of a Gas Oil with High Nitrogen Content ? Energy Fuels, 2019, 33, 1467-1472.

(46) Wei, Q.; Wen, S.; Tao, X.; Zhang, T.; Zhou, Y.; Chung, K.; Xu, C. Hydrodenitrogenation of basic and non-basic nitrogen-containing compounds in coker gas oil. Fuel Processing Technology, 2015, 129, 7684.

(47) Letourneur, D.; Bacaud, R.; Vrinat, M.; Schweich, D.; Pitault, I. Hydrodesulfurization Catalyst Evaluation in an Upflow Three-Phase Microreactor. Ind. Eng. Chem. Res., 1998, 37, 2662-2667. 
(48) Marshall, A. G. Milestones in fourier transform ion cyclotron resonance mass spectrometry technique development. International Journal of Mass Spectrometry, 2000, 200, 331-356.

(49) Wong, S. F.; Meng, C. K.; Fenn, J. B. Multiple charging in electrospray ionization of poly(ethylene glycols). J. Phys. Chem., 1988, 92, 546-550.

(50) Marshall, A. G. Fourier transform ion cyclotron resonance mass spectrometry. Accounts of Chemical Research, 1985, 18, 316-322.

(51) Marshall, A. G.; Hendrickson, C. L.; Jackson, G. S. Fourier transform ion cyclotron resonance mass spectrometry: A primer. Mass spectrometry reviews, 1998, 17, 1-35.

(52) Kendrick, E. A Mass Scale Based on $\mathrm{CH} 2=14.0000$ for High Resolution Mass Spectrometry of Organic Compounds, Anal. Chem., 1963, 35, 2146-2154.

(53) Chainet, F.; Ponthus, J.; Lienemann, C.-P.; Courtiade, M.; Donard, O. F. X. Combining Fourier Transform-Ion Cyclotron Resonance/Mass Spectrometry Analysis and Kendrick Plots for Silicon Speciation and Molecular Characterization in Petroleum Products at Trace Levels. Anal. Chem., 2012, 84, $3998-4005$.

(54) Stihle, J.; Uzio, D.; Lorentz, C.; Charon, N.; Ponthus, J.; Geantet, C. Detailed characterization of coal-derived liquids from direct coal liquefaction on supported catalysts. Fuel, 2012, 95, 79-87.

(55) Li, S.; Liu, N. The transformation of basic nitrogen compounds in coker gas oil during catalytic cracking. Petroleum Science and Technology, 2017, 35, 1141-1145.

(56) Wang, G.; Liu, Y.; Wang, X.; Xu, C.; Gao, J. Studies on the Catalytic Cracking Performance of Coker Gas Oil. Energy Fuels, 2009, 23, 1942-1949.

(57) Girgis, M. J.; Gates, B. C. Reactivities, reaction networks, and kinetics in high-pressure catalytic hydroprocessing. Ind. Eng. Chem. Res., 1991, 30, 2021-2058.

(58) Kasztelan, S.; Des Courières, T.; Breysse, M. Hydrodenitrogenation of petroleum distillates: Industrial aspects. Catalysis Today, 1991, 10, 433-445.

(59) Wiwel, P.; Knudsen, K.; Zeuthen, P.; Whitehurst, D. Assessing Compositional Changes of Nitrogen Compounds during Hydrotreating of Typical Diesel Range Gas Oils Using a Novel Preconcentration Technique Coupled with Gas Chromatography and Atomic Emission Detection. Ind. Eng. Chem. Res., 2000, 39, 533-540. 
(60) Farenc, M.; Paupy, B.; Marceau, S.; Riches, E.; Afonso, C.; Giusti, P. Effective Ion Mobility Peak Width as a New Isomeric Descriptor for the Untargeted Analysis of Complex Mixtures Using lon MobilityMass Spectrometry. Journal of The American Society for Mass Spectrometry, 2017, 28, 2476-2482.

(61) Farenc, M.; Corilo, Y. E.; Lalli, P. M.; Riches, E.; Rodgers, R. P.; Afonso, C.; Giusti, P. Comparison of Atmospheric Pressure lonization for the Analysis of Heavy Petroleum Fractions with Ion Mobility-Mass Spectrometry. Energy Fuels, 2016, 30, 8896-8903.

(62) Lavopa, V. Poisoning of thiophene hydrodesulfurization by nitrogen compounds. Journal of Catalysis, 1988, 110, 375-387.

(63) Ho, T. C.; Katritzky, A. R.; Cato, S. J. Effect of nitrogen compounds on cracking catalysts. Ind. Eng. Chem. Res., 1992, 31, 1589-1597. 